Aus der Abteilung Anaesthesiologie

[Prof. Dr. med. M. Quintel]

im Zentrum Anaesthesiologie, Rettungs- und Intensivmedizin der Medizinischen Fakultät der Universität Göttingen

\title{
Evaluation eines präoperativen Scores für akutes Nierenversagen nach kardiochirurgischen Eingriffen
}

\author{
INAUGURAL-DISSERTATION \\ zur Erlangung des Doktorgrades \\ der Medizinischen Fakultät \\ der Georg-August-Universität zu Göttingen
}

vorgelegt von

Daniela Sundermann

aus

Herford

Göttingen 2010 
Dekan: Prof. Dr. med. C. Frömmel

1. Berichterstatter: PD Dr.med. A. Bräuer

2. Berichterstatter/-in: Prof. Dr. sc. hum. T. Friede

3. Berichterstatter/-in:

Tag der mündlichen Prüfung: $\quad$ 17.08.2011 


\section{Inhaltsverzeichnis}

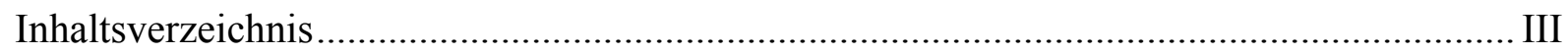

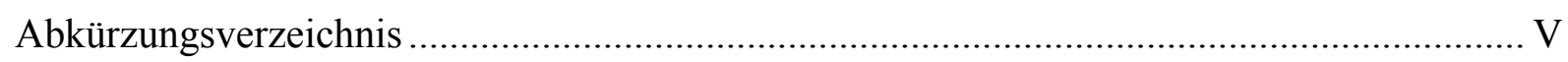

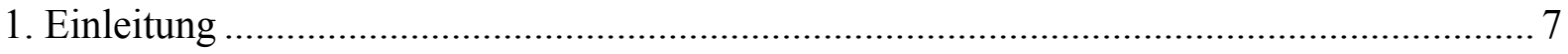

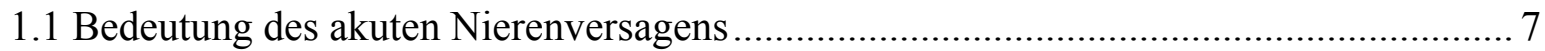

1.2 Risikofaktoren für akutes Nierenversagen ............................................................ 7



1.4 Beschreibung des prognostischen Scores von Thakar ............................................. 9

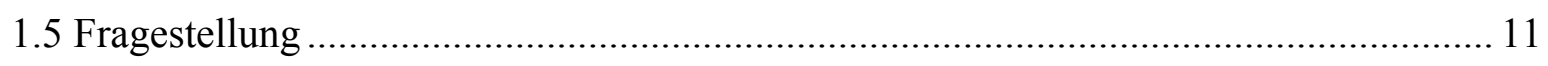

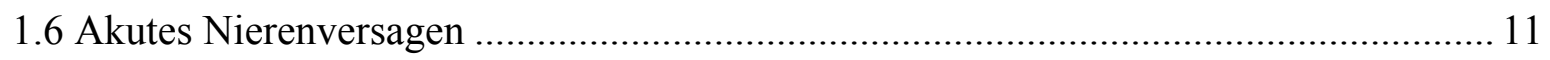

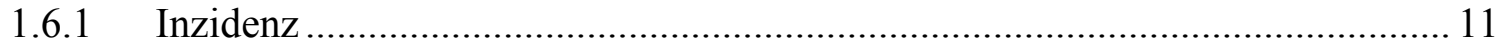

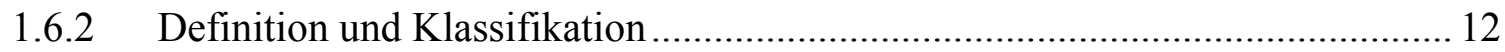

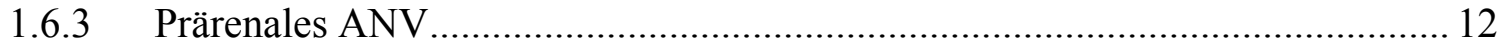

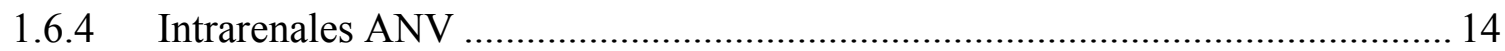

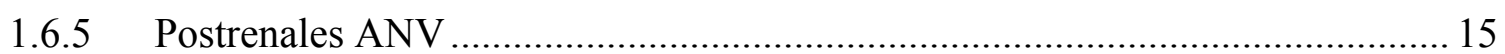

1.6.6 ANV nach kardiochirurgischen Eingriffen .............................................. 16

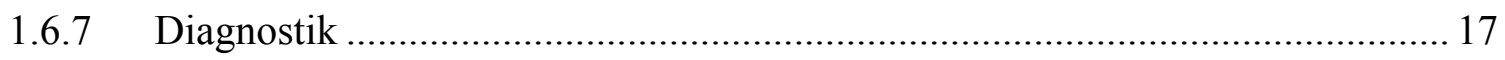

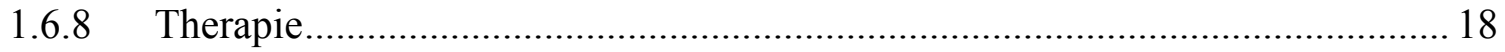

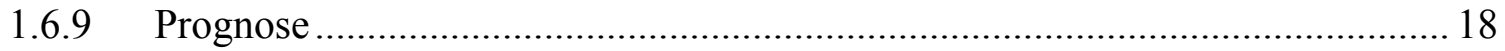

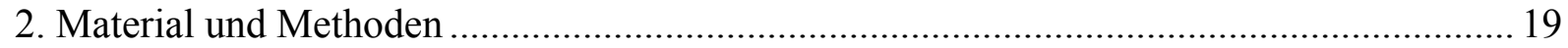

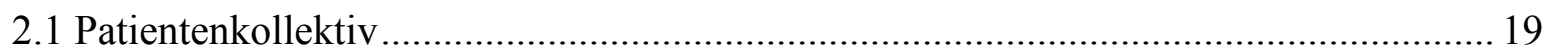

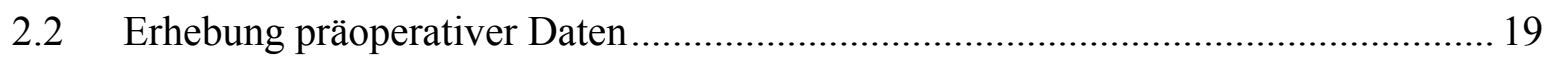

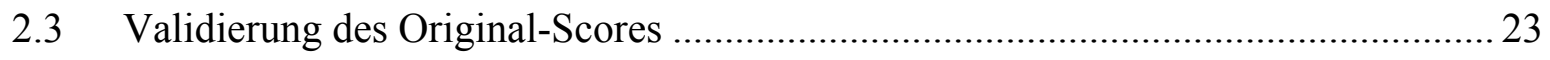

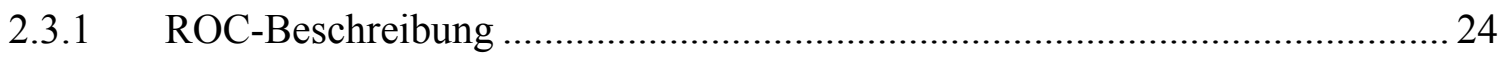

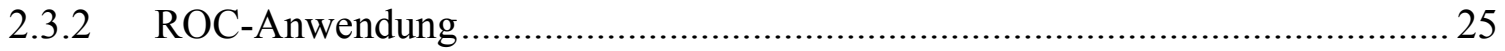



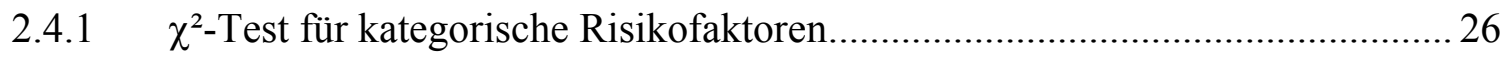

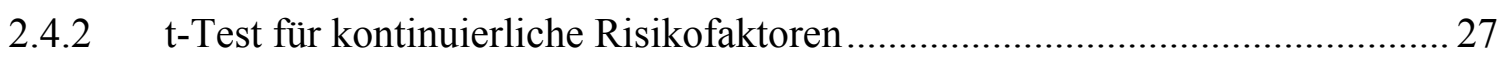

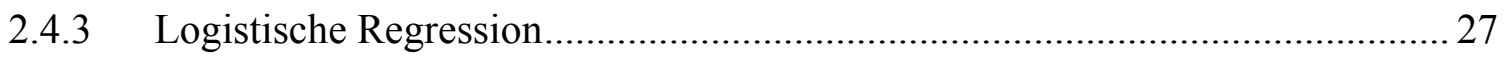

2.4.4 ROC-Analyse mit Göttinger Score-Werten .............................................. 28

2.4.5 Angewandte Software und statistisches Signifikanzniveau ............................ 28 


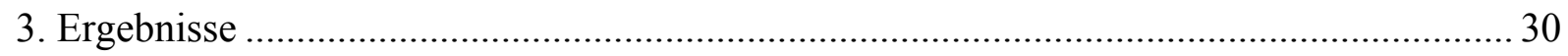

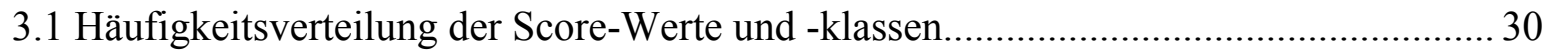

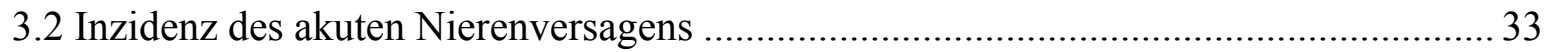

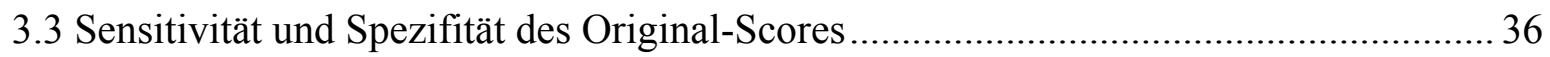



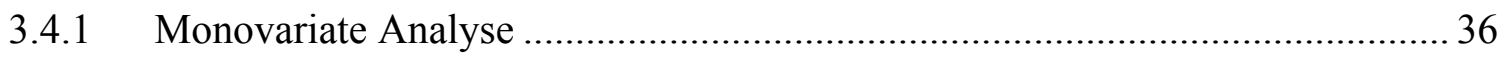

3.4.2 Multivariate Analyse der unterschiedlich verteilten Risikofaktoren.................. 39

3.5 Anwendung des „modifizierten“ Scores im Göttinger Kollektiv .................................. 40

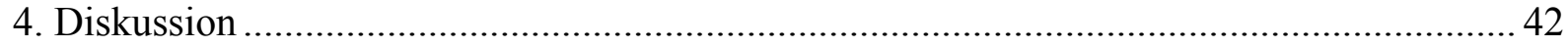

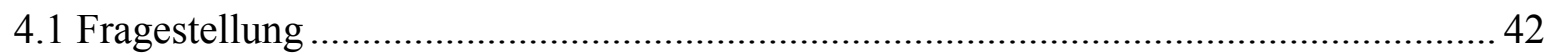

4.1.1 Bedeutung des postoperativen akuten Nierenversagens ............................... 42

4.1.2 Bedeutung der frühzeitigen Erkennung eines ANV ........................................ 42

4.1.3 Limitationen klinisch gebräuchlicher Nierenfunktionsparameter..................... 43

4.1.4 Entwicklung und Stellenwert prognostischer Scores ...................................... 43



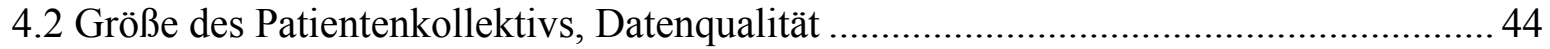

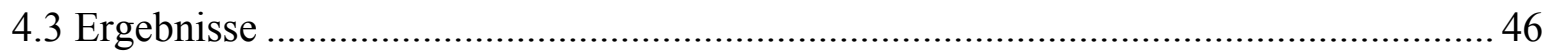

4.3.1 Validierung des Thakar-Scores am Göttinger Kollektiv .................................... 46

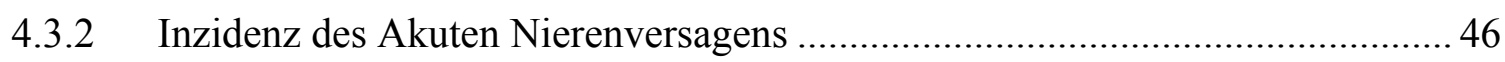

4.3.3 Analyse der einzelnen Risikofaktoren und Modifikation des Original-Scores.. 47





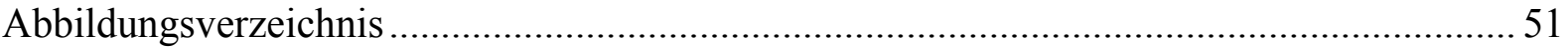



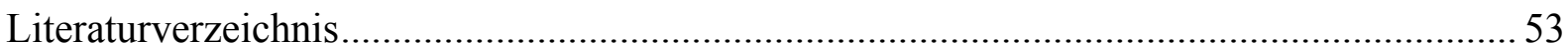




\section{Abkürzungsverzeichnis}

Abb.

Abbildung

ACE

Angiotensin-converting-enzyme

AKIN

Acute Kidney Injury Networks

ANV

Akutes Nierenversagen

ATN

Akute Tubulusnekrose

AT II

Angiotensin II

AUC

Area under curve

COPD

Chronic obstructive pulmonary disease

CT

Computertomographie

d.h.

das heißt

etc.

et cetera

EF

Ejektionsfraktion

GFR

Glomeruläre Filtrationsrate

GISI

Göttinger Informations-System für Intensivmedizin

HLM

Herz-Lungen-Maschine

IABP

Intra-aortic-balloon-pump

IDDM

Insulin-dependent Diabetes mellitus

KI

Konfidenzintervall

KIM

Kidney Injury Molecule

LMW

Low Molecular Weight

LVEF

Linksventrikuläre Ejektionsfraktion

MRT

Magnetresonanztomographie

MW

Mittelwert

NGAL

Neutrophil Gelatinase-associated Lipocalin

NIDDM

Non Insulin-dependent Diabetes mellitus

NYHA

New York Heart Association

o.g.

oben genannte

OP

Operation

OR

Odds Ratio

PEEP

Positive end-expiratory pressure

$\mathrm{RBF}$

Renaler Blutfluss 
RIFLE

ROC

RPGN

S.

SD

Tab.

z.B.

z.T.
Risk-Injury-Failure-Loss-End Stage Renal Disease

Receiver-Operating-Characteristic

Rapidly progressive glomerulonephritis

siehe

standard deviation $=$ Standardabweichung

Tabelle

zum Beispiel

zum Teil 


\section{Einleitung}

\subsection{Bedeutung des akuten Nierenversagens}

Kardiochirurgische Eingriffe gewinnen immer mehr an Bedeutung und die Fallzahlen steigen stetig. Nach Angaben der deutschen Gesellschaft für Thorax-, Herz- und Gefäßchirurgie werden zur Zeit in Deutschland jährlich ca. 100.000 kardiochirurgische Eingriffe durchgeführt (Gummert et al. 2009). Der Fortschritt in der Kardiochirurgie führt dazu, dass operative Eingriffe zunehmend häufig auch bei Patienten mit hohem Lebensalter und einem breiten Profil an Vorerkrankungen durchgeführt werden. Deswegen ist es von großer Bedeutung, Komplikationen dieser Operationen frühzeitig $\mathrm{zu}$ erkennen und $\mathrm{zu}$ therapieren. Eine zentrale Rolle bei der Versorgung postoperativer Patienten spielt das akute Nierenversagen [ANV], da es nicht nur eine hohe Inzidenz aufweist (Provenchere et al. 2003; Martinelli et al. 2009), sondern auch zu einer erheblichen Steigerung der Mortalität führt (Rosner und Okusa 2006). Speziell nach Einsatz der Herz-Lungen-Maschine stellt das ANV eine der häufigsten Komplikationen dar (Bove et al. 2004), die bei ca. 5-30\% der Patienten nach kardiochirurgischen Eingriffen auftritt (Leacche et al. 2006). Bei kardiochirurgischen Patienten steigert ein ANV das Mortalitätsrisiko exponentiell bis auf 60 Prozent (Abel et al. 1976; Frost et al. 1991; Chertow et al. 1997; Mangano et al. 1998; Bent et al. 2001; Thakar et al. 2003 b). Der damit verbundene deutliche Verbrauch an Ressourcen hat ebenfalls eine große Bedeutung für die Intensivmedizin (Mangano et al. 1998; MaWhinney et al. 2000). Zudem verlängert sich die Aufenthaltsdauer im Krankenhaus durch die Komplikation ,akutes Nierenversagen“ (Mehta et al. 2007; Lassnigg et al. 2008).

\subsection{Risikofaktoren für akutes Nierenversagen}

Eine Vielzahl von Studien hat den Einfluss verschiedener Risikofaktoren auf das Entstehen eines ANV untersucht (Yallop und Smith 2004). Ein Teil dieser Risikofaktoren resultiert aus Vorerkrankungen des Patienten und kann somit als präoperative Risikofaktoren zusammengefasst werden. Davon abzugrenzen sind intra- und postoperative Risikofaktoren, die aus operativen bzw. medizinischen Behandlungsstrategien resultieren. Diese 
Unterscheidung ist deshalb sinnvoll, weil präoperative Risikofaktoren nicht mehr modifiziert werden können, während die intra- und postoperative Therapie in gewissen Grenzen individuell angepasst werden kann. $\mathrm{Zu}$ den präoperativen Risikofaktoren zählen das Alter (Sirvinskas et al. 2008), das weibliches Geschlecht (Mitter et al. 2010), eine reduzierte Nierenfunktion (Durmaz et al. 1999), eine eingeschränkte LVEF (Conlon et al. 1999), die präoperative Anlage einer IABP (Doddakula et al. 2007), Notfalleingriffe (Thakar et al. 2005) und Diabetes mellitus (Conlon et al. 1999; Morricone et al. 1999). Mit zu den wichtigsten intraoperativen Risikofaktoren zählt die Bypass-Zeit, d.h. die Zeit, während der die HerzLungen-Maschine den Kreislauf aufrecht erhält (Thakar et al. 2005; Doddakula et al. 2007). Zudem hat auch die Art des kardiochirurgischen Eingriffs einen entscheidenden Einfluss auf die Entstehung eines postoperativen ANV (Morabito et al. 2006). Die signifikantesten postoperativen Risikofaktoren für das Auftreten eines ANV sind Nachblutungen (Oliveira et al. 2010) und Re-Thorakotomien (de Moraes Lobo et al. 2000; Rodrigues et al. 2009).

Präoperative Risikofaktoren spielen eine entscheidende Rolle und sind deshalb von besonderem Interesse, weil sich zum einen aus ihnen die Indikation für den frühzeitigen Einsatz besonders nephroprotektiver Operations- und HLM-Techniken ableiten lassen kann. Zum anderen deuten die Ergebnisse vieler klinischen Studien darauf hin, dass eine Therapie des Nierenversagens möglichst frühzeitig, wenn möglich in den ersten 24 bis 48 Stunden, nach Schädigungsbeginn der Nieren beginnen sollte (Star 1998; Bonventre und Weinberg 2003). Somit können präoperative Risikofaktoren in die Indikationsstellung zur frühzeitigen Nierenersatztherapie mit einbezogen werden.

\subsection{Erkennung des akuten Nierenversagens}

Ein gängiger Parameter zur Beurteilung der Nierenfunktion ist das Serum-Kreatinin, anhand dessen es aber besonders in frühen Stadien schwierig ist, die Diagnose eines postoperativen ANV zu stellen. Da ein hyperboler Zusammenhang zwischen glomerulärer Filtrationsrate [GFR] und Serum-Kreatinin besteht, führt eine beginnende Abnahme der GFR nur zu minimalen Anstiegen des Serum-Kreatinins [sog. Kreatinin-blinder-Bereich der GFR]. Deshalb wurden verschiedene Formeln entwickelt, die die Berechnung der GFR aus dem aktuellen Serum-Kreatinin erlauben, z.B. Cockcroft und Gault-Formel (Cockcroft und Gault 1976), MDRD-Formel (Herold 2010). Da die Halbwertszeit von Kreatinin ca. vier Stunden 
beträgt, stellt sich nach Änderung der GFR ein Steady-state des Serum-Kreatinins jedoch erst nach ca. 20 Stunden ein (Chiou und Hsu 1975).

Zwar konnten diverse aktuelle klinische Studien zeigen, dass tubuläre Nierenfunktionsparameter wie NGAL, Cystatin C oder $\alpha 1$-Mikroglobulin eine deutlich frühzeitigere Erkennung einer akuten Nierenschädigung ermöglichen. Für die gezielte und frühzeitige Anwendung nephroprotektiver Maßnahmen sind jedoch auch diese Parameter nur bedingt geeignet, da signifikante Änderungen erst nach einer stattgehabten Schädigung des Nierenparenchyms zu beobachten sind.

\subsection{Beschreibung des prognostischen Scores von Thakar}

Um intra- und postoperative nephroprotektive Maßnahmen gezielt auf Patienten mit einem hohen ANV-Risiko fokussieren zu können, ist es erforderlich, bereits präoperativ das Risiko eines postoperativen ANV abschätzen zu können.

Aus diesem Grund entwickelte Thakar einen Risikoscore, mit welchem sich die Inzidenz des akuten Nierenversagens aus ausschließlich präoperativen Risikofaktoren präzise voraussagen lässt (Thakar et al. 2005). Der Test wurde an insgesamt 31.677 Patienten entwickelt und validiert, die zwischen 1993 und 2002 einen kardiochirurgischen Eingriff am offenen Herzen erhalten hatten.

Die Entwicklung des Scores erfolgte an der Hälfte [15838] der Patienten, die in zwei Gruppen [ANV bzw. kein ANV] unterteilt wurden, wobei das Kriterium für das Vorliegen eines ANV die Anwendung eines Nierenersatzverfahrens war. Als Indikationen für eine Dialyse wurden Urämie, Volumenüberschuss oder Hyperkaliämie festgelegt.

Aufgrund der Ergebnisse vorausgegangener klinischer Studien (Thakar et al. 2003 a; Thakar et al. 2003 c) wurden 16 Risikofaktoren - zunächst univariat - auf signifikant unterschiedliche Verteilungen in den beiden Patientengruppen untersucht. Hierfür wurde der $\chi^{2}$ - Test für kategorische Risikofaktoren [d.h. solche, die in „,vorhanden“ bzw. „nicht vorhanden“ unterteilt werden können] angewandt wie z.B. COPD, IABP usw. Für die kontinuierlichen Risikofaktoren wie z.B. Alter und Kreatinin wurde der $\mathrm{t}$ - Test für unverbundene Stichproben verwendet.

Anschließend wurde mittels logistischer Regression ermittelt, welcher der verbleibenden, unterschiedlich verteilten Faktoren ein unabhängiges Risiko für das Entstehen eines 
postoperativen ANV darstellt. Da dieses statistische Verfahren auch die Gewichtung der einzelnen Risikofaktoren erlaubt, wurden für die einzelnen Faktoren Punktwerte berechnet und zugewiesen, indem der natürliche Logarithmus der Odds Ratio mit 2 multipliziert und auf den nächsten ganzzahligen Wert aufgerundet wurden. Das Spektrum der Risiko-Punkte reichte von 1 Punkt [weibliches Geschlecht, Herzinsuffizienz, linksventrikuläre EF $<35 \%$, COPD, insulinpflichtiger Diabetes mellitus, Re-Eingriff, OP-Typ Klappeneingriff] bis 5 Punkte [präoperatives Serum-Kreatinin $>2,1 \mathrm{mg} / \mathrm{dl}$ ]. Der maximal mögliche Scorewert bei Vorhandensein aller Risikofaktoren betrug 17 Punkte. Aus dem Ergebnis der logistischen Regression konnte somit ein Score abgeleitet werden, in den 11 der 16 Risikofaktoren eingingen:

Tab. 1 : Risikofaktoren mit zugehörigen Scorepunkten

\begin{tabular}{|l|c|}
\hline \multicolumn{1}{|c|}{ Risikofaktor } & Punktwert \\
\hline Weibliches Geschlecht & 1 \\
\hline Herzinsuffizienz [ab NYHA III ] & 1 \\
\hline Linksventrikuläre Ejektionsfraktion $<35 \%$ & 1 \\
\hline COPD & 1 \\
\hline Insulin-pflichtiger Diabetes mellitus & 1 \\
\hline Re-Eingriff & 1 \\
\hline OP-Typ: & 2 \\
$-\quad$ Klappeneingriff & 2 \\
$-\quad$ Bypass + Klappeneingriff & 2 \\
$-\quad$ Andere kardiochirurg.Eingriffe & 2 \\
\hline Präoperative Anlage einer IABP & 2 \\
\hline Noteingriff Serum-Kreatinin $1,2-$ & 5 \\
\hline Präoperatives & \\
2,0mg/dl & \\
\hline Präoperatives Serum-Kreatinin $\geq 2,1 \mathrm{mg} / \mathrm{dl}$ & \\
\hline
\end{tabular}

Abschließend wurde die $\mathrm{zu}$ erwartende Wahrscheinlichkeit eines postoperativen dialysepflichtigen ANV, inklusive des 95\%-Konfidezintervalls, für das ANV-Risiko in Anhängigkeit des Score-Wertes errechnet. Die Berechnung erfolgte sowohl für alle einzelnen Score-Werte von 0 - 13 als auch für 4 Score-Gruppen [0-2, 3-5, 6-8 und 9-13 Punkte]. 
Die Validierung erfolgte an den verbleibenden 15839 Patienten des Gesamtkollektivs. Der Score zeigte eine gute Kalibration, da die im Validierungskollektiv beobachteten ANVInzidenzen für alle Score-Werte innerhalb der prognostizierten 95\%-Konfidenzintervalle lagen. Sensitivität und Spezifität des Scores für die Voraussage eines ANV wurden mit Hilfe von Receiver-Operation-Characteristic [ROC] ermittelt [siehe Kap. 2.3, Validierung des Original-Scores], wobei der Score ebenfalls eine sehr gute Sensitivität und Spezifität zeigte.

\subsection{Fragestellung}

Trotz der hohen Präzision, mit der die Wahrscheinlichkeit eines postoperativen dialysepflichtigen ANV innerhalb des Validierungs-Kollektivs vorausgesagt werden konnte, diskutierten die Autoren als mögliche Einschränkung, dass der Score an einem monozentrischen Patientenkollektiv entwickelt und validiert worden ist. Ob der qualitative Zusammenhang zwischen steigendem Score-Wert und einer zunehmenden Inzidenz des dialysepflichtigen ANV allgemein auf alle kardiochirurgischen Patienten übertragbar ist, muss ebenso untersucht werden wie die quantitative Übereinstimmung zwischen prognostizierten und tatsächlichen Inzidenzen in den jeweiligen Scorewert-Gruppen. Ziel der vorliegenden Untersuchung ist es daher, die Anwendbarkeit des von Thakar entwickelten Scores an einem kardiochirurgischen Patientenkollektiv eines weiteren Zentrums zu überprüfen.

\subsection{Akutes Nierenversagen}

Das akute Nierenversagen ist definiert als eine akut einsetzende, potentiell jedoch reversible Abnahme der Nierenfunktion, die über Tage anhält. In der Folge kommt es zu einer Retention harnpflichtiger Substanzen und zu einer Störung des Flüssigkeits-, Elektrolyt- und SäureBasen-Haushalts.

\subsubsection{Inzidenz}

Ein bis fünf Prozent aller im Krankenhaus behandelten Patienten und über zehn Prozent der Intensivpatienten entwickeln ein akutes Nierenversagen. Die Inzidenz, verbunden mit einem 
chirurgischen Eingriff, liegt mit bis zu 40 Prozent deutlich höher (Bourgeois et al. 2009; Costantini et al. 2009).

In der Kardiochirurgie tritt das Nierenversagen mit bis zu 17\% Prozent auf (Provenchere et al. 2003; Martinelli et al. 2009).

\subsubsection{Definition und Klassifikation}

Man unterteilt das akute Nierenversagen je nach Genese in ein prärenales, intrarenales und postrenales Versagen, wobei das prärenale Nierenversagen mit $60 \%$, gegenüber dem renalen [35\%] und postrenalen [5\%] Nierenversagen, am häufigsten auftritt (Herold 2010). Darüber hinaus kann das ANV anhand der Urinproduktion in oligurisches [Urinmenge kleiner 500ml pro Tag] oder anurisches Nierenversagen [Urinmenge kleiner 100ml pro Tag] unterschieden werden. Aber auch Normo- bzw. polyurische Verläufe [in 30 Prozent der Fälle] sind möglich, die sich daher nur anhand steigender Retentionswerte diagnostizieren lassen, z.B. eines Anstiegs des Serum-Kreatinins von mehr als 50\% des Ausgangswertes.

\subsubsection{Prärenales ANV}

Unter prärenalem Nierenversagen werden alle Formen des Nierenversagens zusammengefasst, die zu einem kritischen Abfall der glomerulären Filtration führen [s. Tab. 2].

Minderperfusion [Abfall des renalen Blutflusses RBF]

Zum einen können strukturelle Veränderungen $\mathrm{zu}$ einem akuten Abfall der Nierendurchblutung führen. Hierzu zählen Nierenarterienstenosen, Aortendissektionen oder auch thrombembolische Geschehen. Zum anderen können auch funktionelle Störungen eine renale Minderperfusion zur Folge haben. Diese Minderperfusion kann entweder auf eine verminderte kardiale Leistung [z.B kardiogener Schock als Risikofaktor für das Auftreten eines postoperativen akuten Nierenversagens (Conlon et al. 1999) ] oder auf eine Verminderung des Plasmavolumens [Ekksikose, Blutverlust etc.] zurückzuführen sein.

\section{Gestörte Autoregulation}

Unter Autoregulation versteht man die Fähigkeit der Niere, sich an unterschiedliche Blutdruck- und Durchblutungsverhältnisse zu adaptieren. Diese Fähigkeit wird dadurch 
realisiert, dass die zu- und abführenden Gefäße des Glomerulums [Vas afferens und Vas efferens] ihren Widerstand in einem weiten Bereich variieren können. Bei akut abfallendem Blutdruck wird durch eine Weitstellung des Vas afferens eine ausreichende Perfusion gewährleistet, während die gleichzeitige Konstriktion des Vas efferens für den nötigen Filtrationsdruck sorgt. Demgegenüber findet man bei einer Hypertension den gegenteiligen Effekt. Dadurch wird bei systolischen Blutdruckwerten zwischen 80 und $180 \mathrm{mmHg}$ eine konstante glomeruläre Filtration aufrecht erhalten. Bei gestörter Autoregulation kann dagegen bei bereits physiologischen Blutdruckwerten die glomeruläre Filtration beeinträchtigt sein.

Die Vasodilatation des Vas afferens wird durch Prostaglandine vermittelt, die Vasokonstriktion des Vas efferens hingegen durch Angiotensin II. Daher können Medikamente, die in den Prostaglandin- bzw. AT-II- Stoffwechsel eingreifen, zu Störungen in der Autoregulation führen. Hierzu zählen z.B. Nicht-steroidale-Antiphlogistika oder ACEHemmer (Whelton 2000; Gross et al. 2005). Auch Röntgenkontrastmittel können durch eine massive Vasokonstriktion des Vas afferens einen kritischen Abfall der GFR hervorrufen (McCullough 2008).

Tab. 2 : Prärenale Ursachen für akute Niereninsuffizienz (Köhler 1999, S. 1389)

\begin{tabular}{|c|c|}
\hline Hypovolämie & Trauma \\
\hline & Hämorrhagie \\
\hline & Pankreatitis \\
\hline & Gastrointestinale Flüssigkeitsverluste \\
\hline \multirow[t]{4}{*}{ Vermindertes effektives Plasmavolumen } & Nephrotisches Syndrom \\
\hline & Leberversagen \\
\hline & Sepsis, Vasodilatation, Schock \\
\hline & Anästhetika \\
\hline \multirow[t]{4}{*}{ Verminderte kardiale Funktion } & Kardiogener Schock, Herzversagen \\
\hline & Perikardtamponade \\
\hline & Lungenembolie \\
\hline & PEEP-Beatmung \\
\hline \multirow[t]{3}{*}{ Renovaskuläre Minderversorgung } & Atherosklerose \\
\hline & Thrombose \\
\hline & Aortenaneurysma \\
\hline Gestörte Autoregulation & Prostaglandininhibitoren, ACE-Hemmer, Ciclosporine \\
\hline
\end{tabular}


Die für das prärenale Nierenversagen charakteristische Minderperfusion führt zunächst zu einer Beeinträchtigung der glomerulären Filtration. Da das Blut nach der Glomerulumpassage auch für die nutritive Versorgung des kompletten Nierenparenchyms benötigt wird [s. Abb. 1], kann ein länger andauerndes prärenales Nierenversagen zu strukturellen Schädigungen im Tubulssystem führen. Der daraus resultierende Übergang in ein intrarenales Nierenversagen ist somit möglich.

\subsubsection{Intrarenales ANV}

Im Gegensatz zum prärenalen Nierenversagen ist das renale Nierenversagen durch strukturelle Läsionen des Nierenparenchyms definiert [s. Tab. 3].

Da hierbei hauptsächlich das Tubulussystem geschädigt wird, ist ein weiteres Synonym für diese Form des Nierenversagens die ,akute Tubulusnekrose“ [ATN].

Zwar können diese Schädigungen grundsätzlich auch auf eine längerdauernde Minderperfusion zurückzuführen sein. In den meisten Fällen wird das renale Nierenversagen jedoch von Substanzen mit nephrotoxischen Effekten verursacht. Je nach Herkunft und Wirkmechanismus können diese auslösenden Noxen wie folgt eingeteilt werden:

- Exogene Substanzen mit direktem, dosisabhängig toxischem Effekt, z.B. Pharmaka wie Aminoglykoside, Vancomycin oder Amphotericin B (Evenepoel 2004)

- Endogene Substanzen mit direkt toxischem Effekt. Hierbei führt z.B. Hämoglobin aufgrund des Eisenatoms zu Schädigungen des Tubulusepithels, aber auch durch Aggregation zu mechanischer Obstruktion des Tubulussystems (Evenepoel 2004). Weitere Substanzen mit direkter nephrotoxischer Wirkung sind bakterielle Endotoxine oder freie Sauerstoffradikale (Heyman et al. 2000; Basnakian et al. 2002)

- Endogene Substanzen mit indirekt toxischem Effekt. Diese Substanzen führen zur Apoptose von Tubuluszellen (Basnakian et al. 2002; Joannes-Boyau et al. 2010). 
Tab. 3 : Intrarenale Ursachen für akute Niereninsuffizienz (Köhler 1999, S. 1389)

\begin{tabular}{|l|l|}
\hline Prärenale Schädigung & $\begin{array}{l}\text { jede längere Zeit bestehende prärenale Störung kann } \\
\text { zur „renalen“ Schädigung führen }\end{array}$ \\
\hline Tubuläre Läsionen & Postischämie, nephrotische Schädigung \\
\hline \multirow{5}{*}{ Glomeruläre Ursachen } & Medikamente,Aminoglykoside, Kontrastmittel \\
\cline { 2 - 2 } & Anästhetika, Schwermetalle \\
\cline { 2 - 2 } & Myoglobinurie \\
\cline { 2 - 2 } & Leichtkettennephropathie \\
\cline { 2 - 2 } & Hyperkalziämie \\
\hline Kapilläre Ursachen & RPGN \\
\hline & Postinfektiöse Glomerulonephritis \\
\hline Interstitielle Nephritis & Vaskulitiden \\
\hline
\end{tabular}

\subsubsection{Postrenales ANV}

Dem postrenalen Nierenversagen liegt ein Abflusshindernis in den ableitenden Harnwegen mit kompletter oder partieller Obstruktion meist beider Nieren vor. Häufige Ursachen sind Prostatahypertrophie, Blasentumore oder retroperitoneale Hämatome [s. Tab. 4]. Klinisch manifestiert sich diese Form oft mit einer akuten Anurie, die aber auch beim prärenalen und renalen Nierenversagen zu finden ist.

Tab. 4 : Postrenale Ursachen für akute Niereninsuffizienz (Köhler 1999, S. 1390)

\begin{tabular}{|l|l|}
\hline Blasenentleerungsstörung & Harnöhrenstriktur, -obstruktion \\
\hline \multirow{2}{*}{ Ureterobstruktion } & $\begin{array}{l}\text { Blasenhalsobstruktion [Prostatahypertrophie/ } \\
\text {-karzinom] }\end{array}$ \\
\cline { 2 - 2 } & neurogene Blasenentleerungsstörung \\
\hline & Steine, Kristalle, Koagel, Tumoren \\
\hline & Gewebeteile [Papillennekrose] \\
\cline { 2 - 2 } & retroperitoneale Fibrose, Ligatur \\
\hline
\end{tabular}




\subsubsection{ANV nach kardiochirurgischen Eingriffen}

Kardiochirurgische Eingriffe unter Verwendung der HLM führen häufig zu prärenalen, intrarenalen oder kombinierten Nierenfunktionsstörungen. Die unphysiologische [nonpulsatile] Perfusion durch die HLM, postoperatives Low-Cardiac-Output oder Hypovolämien durch Nachblutungen können hierbei ein prärenales Nierenversagen auslösen. Darüber hinaus induziert der Blutkontakt zu den Fremdoberflächen der HLM eine unterschiedlich intensiv ausgeprägte Immunreaktion, die ihrerseits zu renalen Funktionsstörungen führen kann. Aus diesem Grund zählt das ANV gerade bei herzchirurgischen Eingriffen zu den häufigsten Komplikationen.

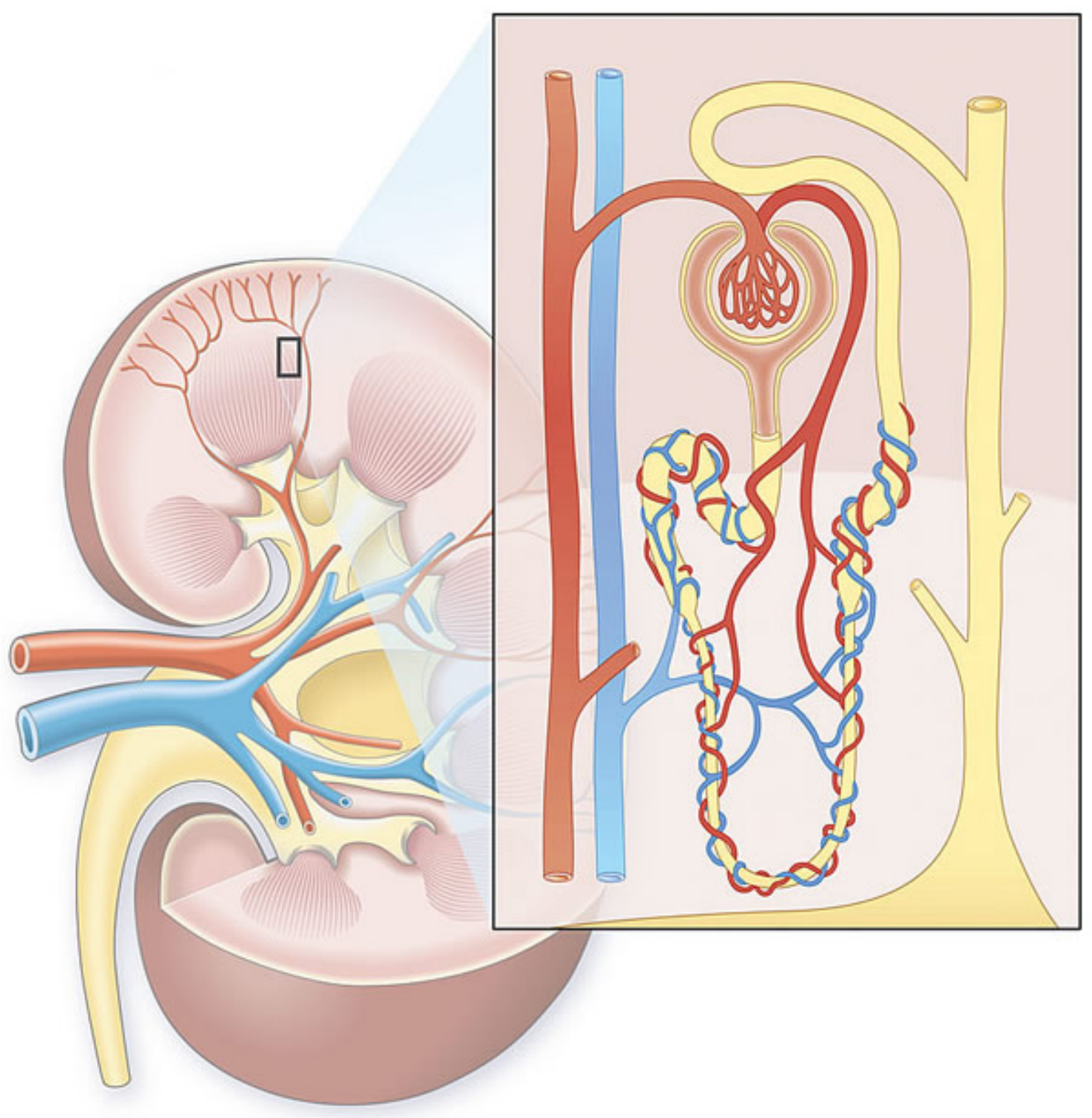

Abb. 1 : Niere

mit Genehmigung von: Wort und Bild Verlag/ Ibelherr/Szczesny (2005) 


\subsubsection{Diagnostik}

In der Diagnostik spielen Anamnese, Klinik, Labor, Diuresemenge und bildgebende Verfahren wie Sonographie, farbkodierte Duplexsonographie, Angio-MRT, Spiral-CT und die perkutane Nierenbiopsie die enscheidende Rolle. Neben der Diagnose ,akutes Nierenversagen“" sollte auch die Ursache des Versagens diagnostiziert werden.

Für das prärenale Nierenversagen insbesondere werden folgende diagnostische Verfahren gewählt:

- Dopplersonographische Messung der Nierendurchblutung

- Labortests für GFR [Serum-Krea, Krea-Clearance, Serum-Cystatin C]

- Hochkonzentrierter Urin, d.h. hohes Verhältnis der Urin/Serum-Konzentrationen von Kreatinin, Natrium etc.

Bei einem intrarenalen Nierenversagen ist zum einen die Konzentrationsfähigkeit des Tubulussystems gestört, d.h. das Verhältnis der Konzentrationen Urin/Serum von Kreatinin, Natrium etc. nimmt stark ab. Zum anderen lassen verschiedene Laborparameter Rückschlüsse auf Rückresorptionsfunktion, Syntheseleistung, strukturelle Integrität oder aber unspezifische Schädigung des Tubulussystems zu. Im Einzelnen:

- Rückresorption von Proteinen: „LMW“-Proteine im Urin [ $\alpha 1$ - oder 32 Mikroglobulin], Cystatin C im Urin

- Rückresorption von Elektrolyten: Fraktionelle Exkretion von Elektrolyten, z.B. fraktionelle Natriumexkretion [,,FeNa“"]

- Syntheseleistung: Tamm-Horsfall-Protein im Urin

- Zellintegrität: Auftreten von obligat intrazellulären Enzymen im Urin wie NAcetylglucosaminidase (Provenchere et al.) oder Lysozm

- Unspezifische Marker einer akuten Tubulusschädigung, deren Synthese bei akutem Tubulusschaden stark hochreguliert wird. Sie können im Serum und Urin gemessen werden. Die bekanntesten sind Kidney Injury Molecule [KIM], Interleukin 18 oder Neutrophiles Gelatinase-Assoziiertes Lipocalin [NGAL]. Besonders NGAL gewinnt immer mehr an Bedeutung, da es ein sensitiver Marker ist, der bereits 1-2 Stunden nach Tubulusschaden extrem erhöht ist. 
Bei der Diagnose des postrenalen Nierenversagens spielen besonders die bildgebenden Verfahren eine zentrale Rolle, da die Folgen eines mechanischen Abflusshindernisses in den meisten Fällen gut dargestellt werden können [Nierenbeckensonographie, Urographie, etc.].

\subsubsection{Therapie}

Die Therapie des akuten Nierenversagens besteht aus drei Grundpfeilern. Erstens muss die zum Nierenversagen führende Grunderkrankung therapiert werden [optimale Schocktherapie, Absetzen nephrotoxischer Medikamente, Revaskularisationsmaßnahmen, urologische Behandlung bei postrenalem Versagen]. Den zweiten Pfeiler stellt die symptomatische Therapie dar. Hierbei spielen die Bilanzierung des Flüssigkeit-Elektrolyt-Haushaltes, die ausreichend kalorienhaltige Ernährung und die Dosisanpassung von Medikamenten die Hauptrolle. Der dritte Pfeiler besteht aus der Nierenersatztherapie zur Behandlung der Azotämie, zum Ausgleich des Flüssigkeit-Elektrolyt-Haushaltes und zur Therapie der metabolischen Azidose.

Da diese Therapiemaßnahmen einerseits so früh als möglich eingesetzt werden sollen, andererseits aus ökonomischen Gründen die breitgestreute Anwendung nicht bei allen Patienten erfolgen kann, ist eine frühzeitige Identifikation von Risikopatienten für den gezielten Einsatz therapeutischer Maßnahmen von großer Bedeutung.

\subsubsection{Prognose}

Die Mortalität des akuten Nierenversagens liegt bei Intensivpatienten trotz großer Fortschritte in der Intensivmedizin in den letzten Jahren unverändert bei 40 Prozent (Bourgeois et al. 2009; Costantini et al. 2009). Das Nierenversagen beeinflusst unabhängig von der Grunderkrankung Komplikationen und Prognosen negativ. Dies liegt zum einen an unmittelbaren Störungen des Volumen- Elektrolythaushaltes und zum anderen auch am ungünstigen Einfluss auf alle biologischen Prozesse und Organfunktionen des Körpers. 


\section{Material und Methoden}

\subsection{Patientenkollektiv}

In dieser Studie wurden retrospektiv Daten von 3628 Patienten analysiert, die in den Jahren 2002 bis 2005 einen kardiochirurgischen Eingriff unter Einsatz der Herz-Lungen-Maschine am offenen Herzen erhalten hatten.

120 Patienten [ ca. 3\%] wurden von der statistischen Analyse ausgeschlossen, da der ScoreWert entweder aufgrund unvollständiger Datensätze nicht errechnet werden konnte oder Ausschlusskriterien [wie z.B. bereits präoperativ bestehendes dialysepflichtiges Nierenversagen] vorlagen. Somit standen für die Validierung des Scores noch 3508 Patienten zur Verfügung.

\subsection{Erhebung präoperativer Daten}

Die Sammlung und Archivierung der erforderlichen Patientendaten erfolgte in MicrosoftExcel. Die Quelle für die Rohdaten war das Patientendatenmanagementsystem GISI [Göttinger Informations-System für Intensivmedizin], aus dem ein Großteil der erforderlichen Daten retrospektiv erhoben werden konnte. Dieses hausintern entwickelte System aus den 80er Jahren wurde in der Mehrheit von den Intensivstationen am Göttinger Universitätsklinikum verwendet. Alle Patienten wurden auf der operativen Intensivstation des Universitätsklinikums Göttingen [Station 0118] behandelt.

Aufgrund der Struktur des Patientendatenmanagementsystems GISI mussten nicht alle für den Score erforderlichen Daten bei der Patientenaufnahme dokumentiert werden. Deswegen war es erforderlich, dass das Vorhandensein einiger Risikofaktoren anhand von Freitextfeldern [Anamnese: Vormedikation etc., s.Abb. 2, 3 rechts unten] überprüft wurde.

Unabhängig davon konnte das Vorhandensein nicht aller Risikofaktoren objektiv beurteilt werden [s.Tab. 5]. Dies war z.B. möglich bei dem Geschlecht oder Art des Eingriffs [s.Abb. 4, 6] . Ein Beispiel für subjektive, also der Interpretation des Auswerters unterliegende Risikofaktoren ist z.B. Herzinsuffizienz. So kann dieser Risikofaktor zwar objektiv anhand 
der NYHA-Klassifikation beurteilt werden, jedoch mussten beim Fehlen der NYHA-Angabe subjektive Symptome des Patienten interpretiert werden.

Nach der NYHA-Klassifikation wird folgendermaßen eingeteilt:

Schweregrad 1 : keine Leistungseinschränkung bei gewöhnlicher Belastung

Schweregrad 2 : leichte Einschränkung der körperlichen Belastbarkeit

Schweregrad 3 : Beschwerden bei geringer körperlicher Belastbarkeit

Schweregrad 4 : manifeste Herzinsuffizienz bereits in Ruhe.

So waren Begriffe wie „gewöhnliche Belastung“ oder „leichte Einschränkung“ von der Interpretation abhängig.

Tab. 5 : Einteilung der erforderlichen Daten

\begin{tabular}{|c|c|c|}
\hline & Obligat & Fakultativ \\
\hline Objektiv & $\begin{array}{ll}- & \text { Alter } \\
- & \text { Geschlecht } \\
- & \text { OP-Art [Klappe, Bypass, } \\
& \text { Klappe + Bypass] } \\
- & \text { präoperatives Kreatinin }\end{array}$ & $\begin{array}{ll}- & \text { IDDM } \\
- & \text { EF }<35 \% \\
- & \text { präoperative Anlage einer } \\
& \text { IABP }\end{array}$ \\
\hline Subjektiv & & $\begin{array}{ll}\text { - } & \text { Herzinsuffizienz } \\
\text { - } & \text { COPD }\end{array}$ \\
\hline
\end{tabular}

Demnach waren bei jedem Patienten definitiv die Angaben Alter, Geschlecht und die Art des kardiochirurgischen Eingriffs dokumentiert. Die Anlage einer IABP dagegen wurde entweder in einem Kontrollkästchen markiert oder eine Eingabe mit Datum der Anlage einer IABP im Freitextfeld getätigt. Die weiteren Risikofaktoren COPD, Insulin-pflichtiger Diabetes mellitus, Herzinsuffizienz und die linksventrikuläre Ejektionsfraktion bezogen sich auf die Anamnese und mussten daher anhand eines Freitextfeldes bewertet werden [s.Abb. 3].

Das präoperative Kreatinin war nur teilweise im GISI-Programm angegeben, so dass aus dem Laborsystem des Göttinger Universitätsklinikums IXSERV die noch fehlenden Daten ergänzt wurden. 


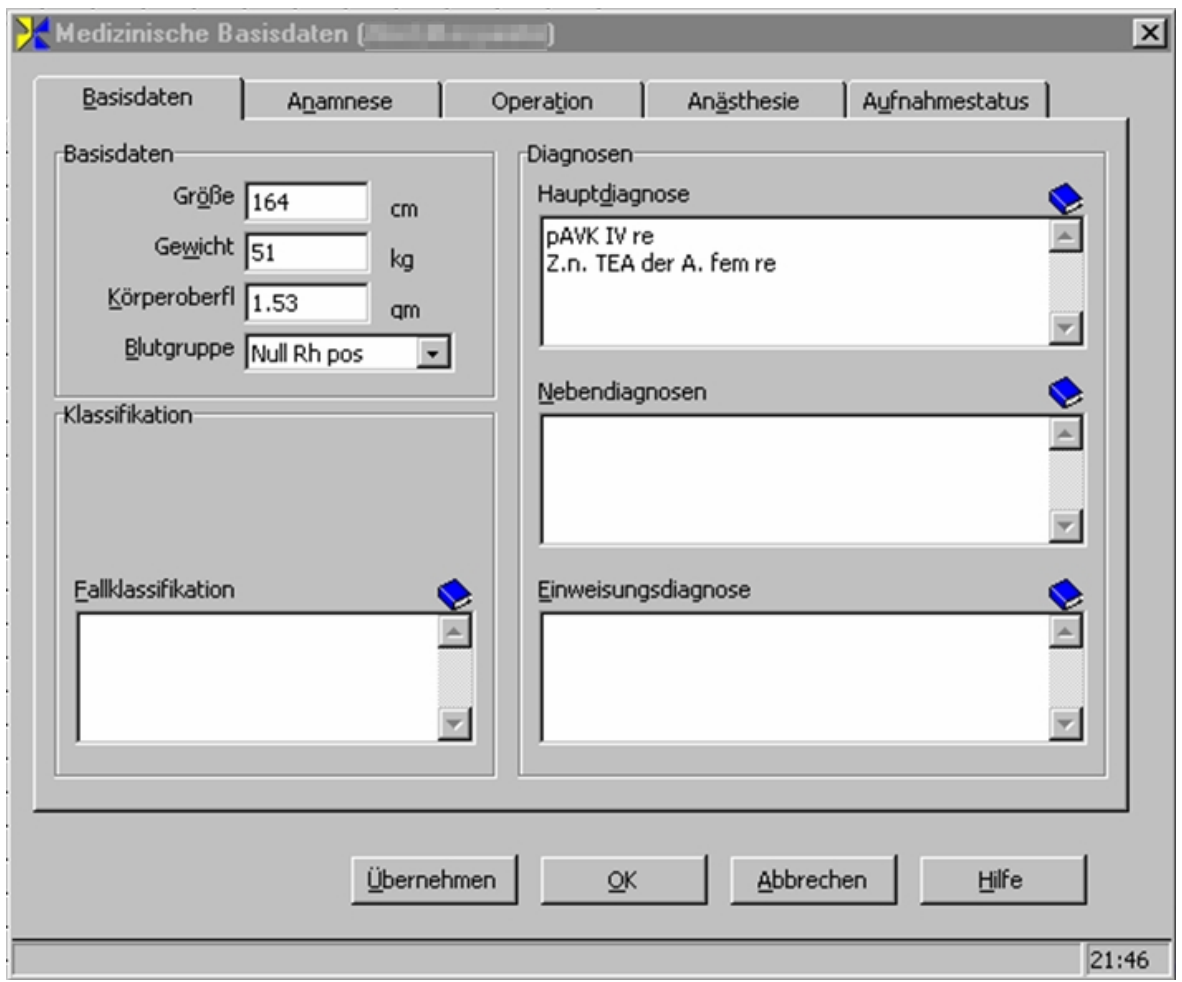

Abb. 2 : GISI-Maske mit obligaten Daten

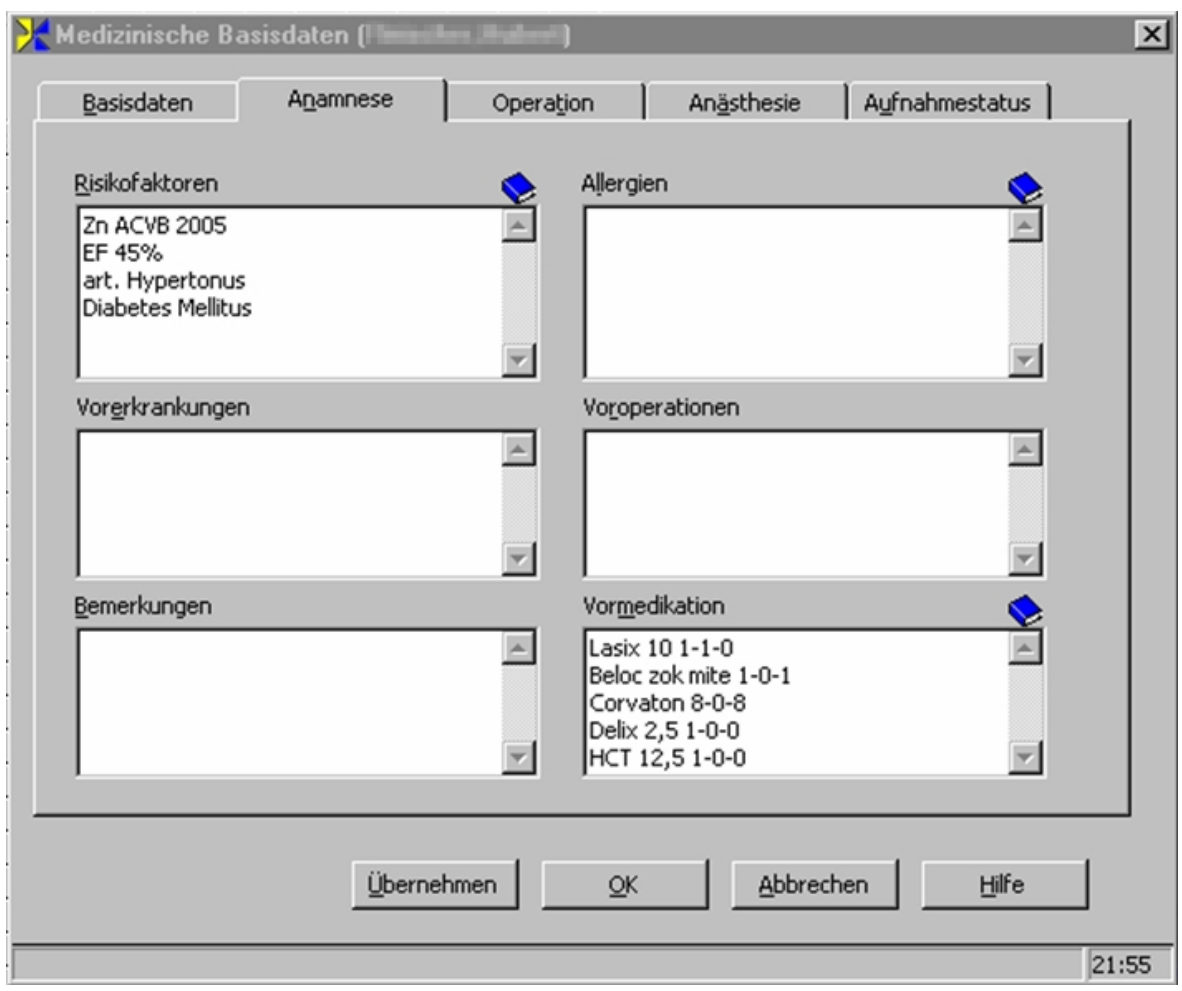

Abb. 3 : GISI-Maske mit fakultativen Daten: objektiv [links], subjektiv [rechts] 
herzchirurgischer Eingriff

konventionell

AKE minimalinvasiv

Coro minimalinvasiv

Kinder minimalinvasiv

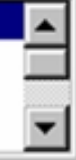

$\sqrt{v}$ HLM-Operation

partielle Bypasszeit

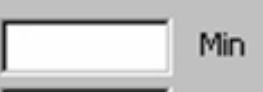

totale Bypasszeit

Min

Ischämiezeit 89

Min

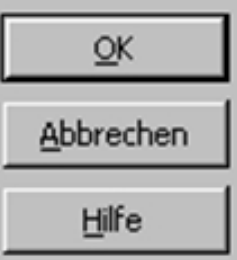

Ausfuhr

$$
\text { Urinmenge } 1500
$$

$\Gamma$ Hämofiltration

Fitratmenge

$\mathrm{ml}$

Abb. 4 : GISI-Maske mit objektiv-obligaten Daten am Beispiel: Art des kardiochirurgischen Eingriffs

Besonderheiten im Verlauf (Hin Antri)

口回区

Beghandlung Ansicht Hille

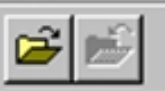

\begin{tabular}{|c|c|c|c|c|}
\hline Datum & Zeit & Besonderheit im Verlauf & Kommentar & $\Delta$ \\
\hline 10.12 .2005 & $11: 32$ & Hämofiltration & beendet am 12.12.05, 09:15 & \\
\hline 07.12 .2005 & $10: 24$ & Hämofiltration & beendet am $07.12 .05,17: 22$ & \\
\hline 05.12 .2005 & $21: 06$ & Hämofiltration & beendet am 07.12.05, 05:43 & \\
\hline 04.12 .2005 & $19: 26$ & Hämofiltration & beendet am 05.12.05, 20:42 & \\
\hline 01.12 .2005 & $18: 09$ & Hämofiltration & beendet am $03.12 .05,07: 12$ & \\
\hline 30.11 .2005 & $14: 37$ & Hämofiltration & beendet am 01.12.05, 09:55 & \\
\hline 29.11 .2005 & $17: 37$ & Hämofiltration & beendet am $30.11 .05,11: 10$ & \\
\hline 27.11 .2005 & $18: 59$ & Hämofiltration & beendet am $29.11 .05,12: 33$ & \\
\hline 25.11 .2005 & $15: 59$ & Hämofiltration & beendet am 27.11.05, 17:39 & \\
\hline 25.11 .2005 & $05: 31$ & Hämofiltration & beendet am $25.11 .05,08: 18$ & \\
\hline 24.11 .2005 & $16: 49$ & Hämofiltration & beendet am $25.11 .05,03: 55$ & \\
\hline 23.11 .2005 & $15: 27$ & Hämofiltration & beendet am 24.11.05, 13:56 & $\nabla$ \\
\hline
\end{tabular}

Abb. 5 : GISI-Maske für das Merkmal ANV / kein ANV 


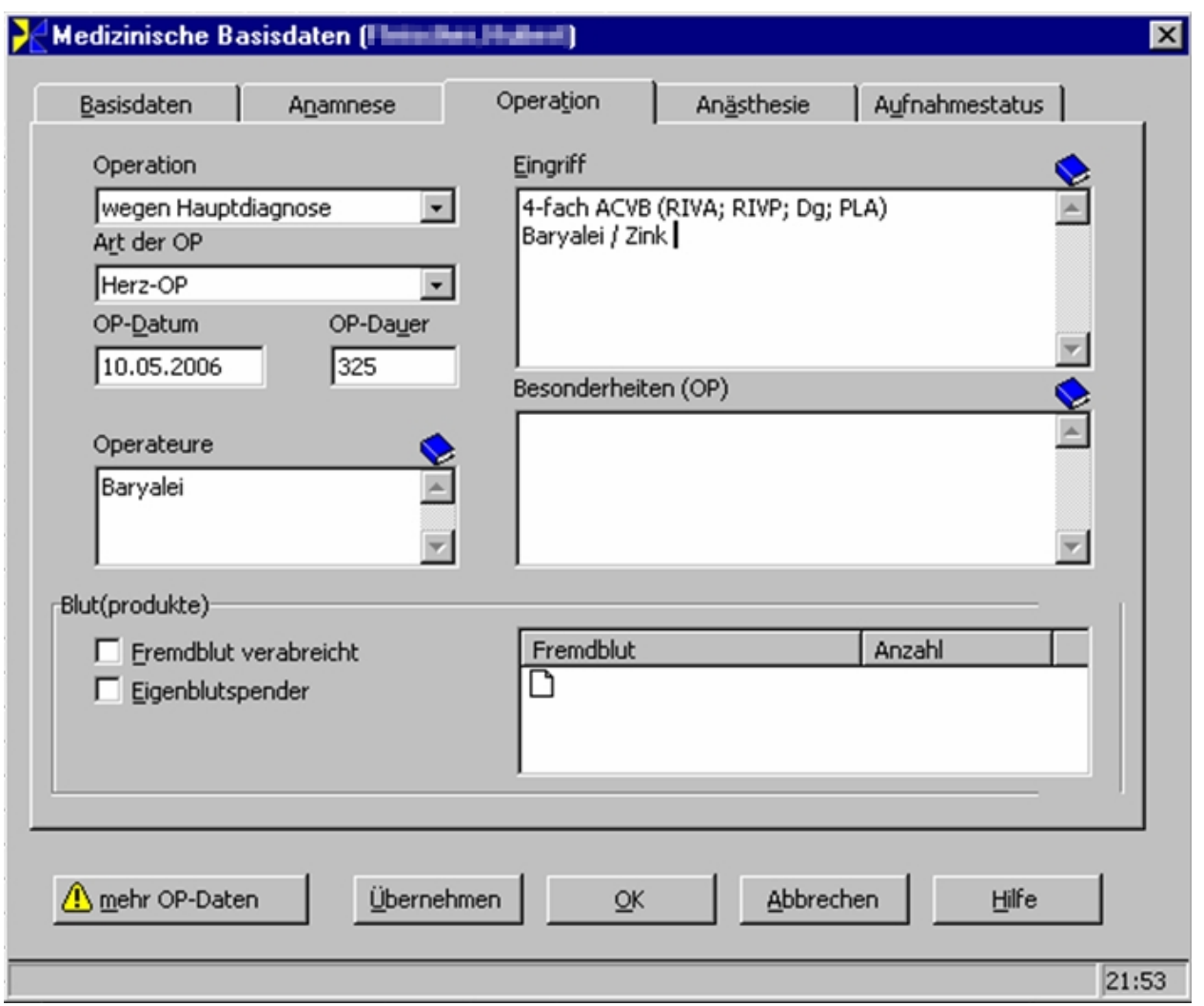

Abb. 6 : GISI-Maske mit objektiv-obligaten Daten am Beispiel: Art des kardiochirurgischen Eingriffs in Form eines Freitextfeldes

Als Kriterium für akutes Nierenversagen wurde, wie beim Original-Score von Thakar, die Anwendung eines Nierenersatzverfahrens gewählt. Diese Information war für jeden Patienten in obligatorischer Form gespeichert, so dass eine objektive Zuordnung zu den beiden Gruppen ANV bzw. kein ANV möglich war [s.Abb. 5]. Per Definition war die Indikation zur Dialyse gegeben, wenn eine Urämie, Volumenüberschuss oder Hyperkaliämie vorlag.

\subsection{Validierung des Original-Scores}

Sensitivität und Spezifität des Thakar-Scores, für die Voraussage eines dialysepflichtigen Nierenversagens innerhalb des Göttinger Patientenkollektives, wurden mittels ReceiverOperating-Characteristic-Analyse [ROC] errechnet. 


\subsubsection{ROC-Beschreibung}

Die ROC-Analyse ist ein Verfahren, mit dem die Sensitivität und Spezifität eines diagnostischen Tests quantifiziert werden kann.

Die Sensitivität gibt bei einem statistischen Test die Wahrscheinlichkeit an, einen tatsächlich positiven Sachverhalt auch durch ein positives Testergebnis zu erkennen. Die Sensitivität gibt also den Anteil der richtig als positiv [richtig positiv] erkannten Sachverhalte an der Gesamtheit der in Wirklichkeit positiven Sachverhalte an.

Die Spezifität hingegen drückt die Wahrscheinlichkeit aus, einen tatsächlich negativen Sachverhalt durch ein negatives Testergebnis zu erkennen. Das bedeutet, dass die Spezifität somit den Anteil der richtig als negativ [richtig negativ] erkannten Sachverhalte an der Gesamtheit der in Wirklichkeit negativen Sachverhalte angibt.

Wenn ein dichotomes Testergebnis [positiv/negativ] anhand einer kontinuierlichen Variablen beurteilt werden soll, hängen Sensitivität und Spezifität wesentlich vom gewählten Grenzwert der Variablen [sog. Cut-off-Point] ab. Wählt man den Cut-Off-Wert niedrig, resultiert eine hohe Sensitivität, aber eine niedrige Spezifität. Bei einem hoch gewählten Cut-Off-Wert ist die Sensitivität gering, aber die Spezifität hoch.

Berechnet man für eine Reihe von Cut-off-Punkten innerhalb des Bereiches aller möglichen Testergebnisse die dazugehörigen Spezifitäten und Sensitivitäten, kann man die Wertepaare in Form eines Graphen darstellen.

Liegen die Punkte genau auf der Diagonalen, bedeutet dies, dass der Test keine diagnostische Aussagekraft besitzt, da der Anteil der richtig klassifizierten gleich dem Anteil der falsch klassifizierten Patienten entspricht. Da man möglichst eine hohe Spezifität und Sensitivität der Ergebnisse anstrebt, sind Ergebnisse, die in den unteren rechten Teil des Koordinatensystems fallen, nicht aussagekräftig. Anhand des ROC-Graphen kann derjenige Cut-off-Punkt identifiziert werden, der mit der höchsten Spezifität und Sensitivität behaftet ist [s. Abb. 7]. 


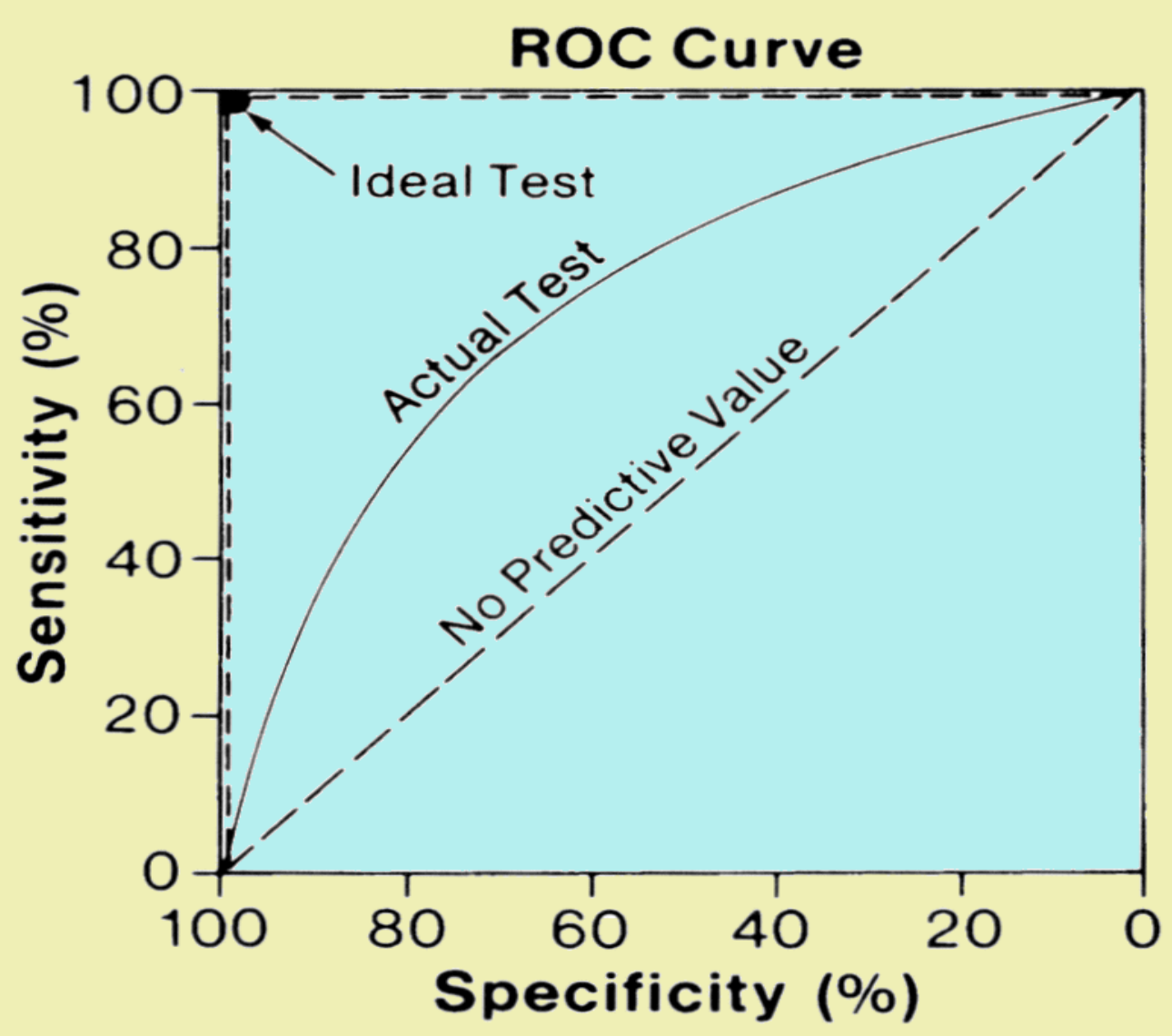

Abb. 7 : Beispiel ROC-Kurve

Darüber hinaus kann die diagnostische Ausagekraft eines Tests mit der Fläche quantifiziert werden, die der Graph unter sich einschließt [Area under the Curve oder auch AUC). Der AUC-Wert kann dabei Werte zwischen null und eins besitzen. Ein Wert von 0,5 beispielsweise würde keine Aussagekraft haben und einfachem Raten entsprechen. Dementsprechend sollte der Wert über 0,5 liegen, weil ein höherer Wert die bessere Güte anzeigt.

Deshalb erlaubt dieses Verfahren eine Gegenüberstellung von Testergebnissen, die in verschiedenen Kollektiven erhoben wurden.

\subsubsection{ROC-Anwendung}

Für 3508 Patienten wurde anhand ihres individuellen Score-Wertes und anhand des Kriteriums ,akutes Nierenversagen / kein akutes Nierenversagen“ eine ROC-Kurve erstellt. 
Dabei wurde für jeden Cut-off-Punkt das zugehörige Wertepaar [ Sensitivität; 1- Spezifität ] in ein Koordinaten-System aufgetragen.

Hieraus wurde die Fläche unter der Kurve [AUC] einschließlich der 95\%-Konfidenzintervalle [KI] errechnet, um die diagnostische Aussagekraft des Original-Scores für das Göttinger Kollektiv quantifizieren zu können.

\subsection{Modifizierter Score}

Anschließend wurde überprüft, ob die Risikofaktoren des Thakar-Scores im Göttinger Patientenkollektiv eine ähnliche Gewichtung zeigten wie in den Kollektiven aus Cleveland. Hierzu wurden die Einflussfaktoren zunächst univariat auf unterschiedliche Verteilung in den Patientengruppen [mit bzw. ohne dialysepflichtiges Nierenversagen] mittels $\chi^{2}$-Test und t-Test untersucht.

\subsection{1 $\quad \chi^{2}$-Test für kategorische Risikofaktoren}

Die Verteilung [nominaler] kategorischer Größen wurde mittels $\chi^{2}$-Test analysiert.

Der $\chi^{2}$-Test wird angewandt, um zu überprüfen, ob die Ausprägung eines Merkmals in verschiedenen Untergruppen gleich verteilt ist. Der „klassische“ $\chi^{2}$-Test ist die 4-Felder Tafel, in der das Merkmal nur zwei Ausprägungen hat [ja / nein] und seine Verteilung in zwei Gruppen verglichen wird. Während in der vorliegenden Studie die Anzahl der Gruppen immer zwei betrug [ANV / kein ANV], lagen die Merkmale „Diabetes“ und „OP-Art“ in drei bzw. vier Ausprägungen vor [Diabetes: insulinpflichtig, nicht insulinpflichtig, kein Diabetes, OP-Art: Bypass, Klappen-OP, Klappe + Bypass, andere]. Alle anderen nominalen Merkmale lagen in zwei Ausprägungen vor, nämlich „,vorhanden“ oder „,nicht vorhanden“, als Beispiel COPD [s.Tab. 6].

Tab. 6 : Beobachtete Häufigkeiten in einer Kreuztabelle

\begin{tabular}{|l|l|l|}
\hline COPD & ANV & kein-ANV \\
\hline Vorhanden $[\mathrm{N}=491]$ & 62 & 429 \\
\hline Nicht vorhanden $[\mathrm{N}=3017]$ & 321 & 2696 \\
\hline
\end{tabular}


Das Ergebnis des Tests ist die Kenngröße $\chi^{2}$. Aus dieser Größe und der Anzahl $n$ kann anhand der festgelegten Irrtumswahrscheinlichkeit für die Annahme, dass die Verteilung in beiden Gruppen unterschiedlich ist, der p-Wert ermittelt werden [s.Tab. 7]. Bei der vorliegenden Untersuchung lag die Anzahl der Freiheitsgrade bei 1, so dass für die Größe $\chi^{2}$ ein Grenzwert von 3,841 festgelegt wurde.

Tab. $7: \chi^{2}$-Verteilung (Weiss C. 2010, S. 334)

\begin{tabular}{|c|r|r|r|r|r|}
\hline $\mathrm{f}=$ Freiheitsgrad & $\chi^{2} \mathrm{f} ; 0,90$ & $\chi^{2} \mathrm{f} ; 0,95$ & $\chi^{2} \mathrm{f} ; 0,975$ & $\chi^{2} \mathrm{f} ; 0,99$ & $\chi^{2} \mathrm{f} ; 0,995$ \\
\hline 1 & 2,706 & 3,841 & 5,024 & 6,635 & 7,879 \\
2 & 4,605 & 5,991 & 7,378 & 9,21 & 10,597 \\
3 & 6,251 & 7,815 & 9,348 & 11,345 & 12,838 \\
\hline
\end{tabular}

\subsection{2 t-Test für kontinuierliche Risikofaktoren}

Der t-Test wird verwendet, um kontinuierliche Größen, wie zum Beispiel präoperatives Kreatinin, auf unterschiedliche Verteilung hin zu untersuchen. Für die Anwendung des Tests ist es wichtig, dass die Größen normal verteilt sind. Da die Kollektive mit ANV bzw. ohne ANV miteinander verglichen wurden, kam der t-Test für unverbundene Stichproben zur Anwendung. Die mit dem t-Test analysierten Risikofaktoren waren rational- skaliert, d.h. dass nicht nur der Abstand der Messwerte, sondern auch deren Nullpunkt definiert war. Der Test liefert als Ergebnis die Irrtumswahrscheinlichkeit $p$, mit der die Nullhypothese der Annahme gleicher Mittelwerte in den Gruppen abgelehnt werden kann.

\subsubsection{Logistische Regression}

In einem zweiten Schritt wurden diejenigen Faktoren, die in den Gruppen signifikant unterschiedlich verteilt waren, auf ihren unabhängig voneinander bestehenden Einfluss auf die Entstehung eines ANV überprüft. Hierfür wurde als Verfahren eine multivariate Analyse mittels logistischer Regression angewandt.

Die logistische Regression ermittelt eine Funktionsgleichung, die den quantitativen Einfluss mehrerer Faktoren auf ein dichotomes Endergebnis beschreibt.

Die logistische Regression liefert als Ergebnis für jeden Risikofaktor einen Regressionskoeffizienten. Potenziert man die Eulersche Zahl $e$ mit dem Regressionskoeffizienten, resultiert daraus die „Odds Ratio“[OR] für den jeweiligen 
Risikofaktor. Die Odds-Ratio ist der Faktor, um den das Risiko für die Entstehung des Endergebnisses steigt, wenn der betreffende Risikofaktor vorliegt. OR $=1$ bedeutet keinen Einfluss auf das Auftreten des Endergebnisses. OR $>1$ bedeutet, dass der Risikofaktor das Auftreten des Endergebnisses begünstigt. Angegeben werden auch die 95\%Konfidenzintervalle der OR, d.h. der Bereich, in dem die OR mit 95\%iger Sicherheit liegt. Der Einfluss eines Risikofaktors auf das Endergebnis kann mit einer Irrtumswahrscheinlichkeit $<5 \%$ als gegeben angesehen werden, wenn das 95\%Konfidenzintervall der Odds Ratio nur Werte über 1 oder unter 1 enthält [z.B. 1,2 - 2,8 , nicht aber $0,7-5,6]$.

Entsprechend der Methodik von Thakar wurden für alle Risikofaktoren mit unabhängigem Einfluss auf das Ergebnis ANV Scorepunkte errechnet, indem der Regressionskoeffizient mit 2 multipliziert und auf den nächsten ganzzahligen Wert gerundet wurde.

\subsubsection{ROC-Analyse mit Göttinger Score-Werten}

Der so entstandene modifizierte Score wurde abschließend mittels ROC-Analyse auf seine Sensitivität und Spezifität für die Voraussage eines dialysepflichtigen Nierenversagens innerhalb des Göttinger Kollektivs untersucht.

\subsubsection{Angewandte Software und statistisches Signifikanzniveau}

Die statistische Auswertung der Daten erfolgte mit der Software „MedCalc ${ }^{\circledR}$ “ Version 9.3 [MedCalc Software, Mariakerke, Belgien].

Als Grenzwert für statistische Signifikanz wurde $\mathrm{p}<0,05$ festgelegt [s.Tab. 8]

Dieser p-Wert beschreibt die Wahrscheinlichkeit, dass die formulierte Nullhypothese irrtümlicherweise abgelehnt wird. Die Nullhypothesen für den $\chi^{2}$ - bzw. t-Test gehen von einer Gleichverteilung in beiden Gruppen aus. Die Nullhypothese für die logistische Regression dagegen besagt, dass die Risikofaktoren keinen unabhängigen Einfluss auf das Endergebnis haben. 
Tab. 8 : p-Wert Aussagen

\begin{tabular}{|l|l|}
\hline Irrtumswahrscheinlichkeit & Bedeutung \\
\hline $\mathrm{P}>0,05$ & Nicht signifikant \\
\hline $\mathrm{p} \leq 0,05$ & Signifikant \\
\hline $\mathrm{P} \leq 0,01$ & Sehr signifikant \\
\hline $\mathrm{P} \leq 0,001$ & Höchst signifikant \\
\hline
\end{tabular}




\section{Ergebnisse}

\subsection{Häufigkeitsverteilung der Score-Werte und -klassen}

Aus den einzelnen Risikofaktoren, die jeweils ein Patient aufzuweisen hatte, ergab sich der individuelle Score-Wert. Die im Göttinger Kollektiv erreichten Scorewerte hatten eine Spanne von 0-11. Im Cleveland-Kollektiv wurden die Score-Werte 0-13 vergeben, wobei Patienten mit den Scorewerten 12 und 13 einen Anteil von insgesamt 0,05\% am gesamten Kollektiv ausmachten.

Im Vergleich mit Cleveland war die Verteilung der prozentualen Anteile der Patienten auf die einzelnen Score-Werte in Göttingen fast identisch. Einen Score-Wert von null hatten in Göttingen 13,28\% der Patienten, in Cleveland 13,4\% der Patienten [s.Tab. 9, s.Abb. 8].

Der Anteil am Gesamtkollektiv stieg bei den Score-Werten eins und zwei an. Der häufigste erreichte Score-Wert war in beiden Kollektiven zwei [in Göttingen 21,58 \% und in Cleveland 22,31 \% der Patienten). Ab dem Score-Wert drei fiel der Anteil der zugehörigen Patienten wieder ab. Dieses bedeutet, höhere Score-Werte wurden von weniger Patienten erreicht.

Der höchste in Göttingen erreichte Score-Wert von 11 war, wie auch in Cleveland, mit einem Anteil von $0,09 \%$ der Patienten vertreten.

Ebenso wie in der Original-Arbeit von Thakar (Thakar et al. 2005) wurden die Score-Werte als Risiko-Gruppen zusammengefasst. Hieraus ergaben sich die vier Risiko-Gruppen 0-2, 3-5, 6-8 und 9-13, wodurch sich ein besserer Überblick und auch Vergleich ergaben.

Auch hier zeigte sich im Vergleich der beiden Kollektive eine nahezu identische Verteilung in den einzelnen Gruppen. Die größte Gruppe bildete dabei die Score-Gruppe mit den Werten von null bis zwei [s.Tab. 10, s.Abb. 9] . Diese war in Göttingen mit einem Anteil von 53,93 \% und in Cleveland mit einem Anteil von 53,14 \% vertreten. Danach fiel in den nachfolgenden Gruppen [wie schon oben erwähnt] der Anteil am Gesamtkollektiv ab. So war die Gruppe mit einem Score-Wert von drei bis fünf mit einem Anteil von 37,66 \% in Göttingen und 38,5 \% in Cleveland auszumachen. Auf die Score-Gruppe von sechs bis acht Punkten entfielen in Göttingen 7,27 \% der Patienten am Gesamtkollektiv, im Kollektiv von Cleveland betrug der Anteil 7,46 \%. Auf die letzte Score-Gruppe mit Score-Werten von neun bis dreizehn entfielen in Göttingen 1,14 \% und in Cleveland 0,91 \% der Patienten. 
Tab. 9 : Verteilung der einzelnen Score-Werte

\begin{tabular}{|c|c|c|c|c|}
\hline & \multicolumn{2}{|l|}{$\begin{array}{l}\text { Cöttingen } \\
\text { Häufigkeit der Score-Werte }\end{array}$} & \multicolumn{2}{l|}{$\begin{array}{l}\text { Cleveland } \\
\text { Häugkeit der Score-Werte }\end{array}$} \\
\hline Score-Punkte & $\mathrm{N}$ & $\%$ & $\mathrm{~N}$ & 13,40 \\
\hline 0 & 466 & 13,28 & 2123 & 17,43 \\
1 & 669 & 19,07 & 2760 & 22,31 \\
2 & 757 & 21,58 & 3533 & 18,62 \\
3 & 614 & 17,50 & 2949 & 11,97 \\
4 & 451 & 12,86 & 1896 & 7,91 \\
5 & 256 & 7,30 & 1252 & 4,33 \\
6 & 140 & 3,99 & 685 & 2,04 \\
7 & 74 & 2,11 & 323 & 1,09 \\
8 & 41 & 1,17 & 173 & 0,52 \\
9 & 26 & 0,74 & 82 & 0,25 \\
10 & 11 & 0,31 & 40 & 0,09 \\
11 & 3 & 0,09 & 14 & 0,04 \\
12 & 0 & 0,00 & 7 & 0,01 \\
\hline
\end{tabular}

Tab.10 : Verteilung der Risiko-Gruppen

\begin{tabular}{|c|c|c|c|c|}
\hline & \multicolumn{2}{|l|}{$\begin{array}{l}\text { Göttingen } \\
\text { Häufigkeit der Score-Werte }\end{array}$} & \multicolumn{2}{l|}{$\begin{array}{l}\text { Cleveland } \\
\text { Häufigkeit der Score-Werte }\end{array}$} \\
\hline Risiko-Gruppen & $\mathrm{N}$ & $\%$ & $\mathrm{~N}$ & $\%$ \\
\hline $0-2$ & 1892 & 53,93 & 8416 & 53,14 \\
$3-5$ & 1321 & 37,66 & 6097 & 38,50 \\
$6-8$ & 255 & 7,27 & 1181 & 7,46 \\
$9-13$ & 40 & 1,14 & 144 & 0,91 \\
\hline
\end{tabular}




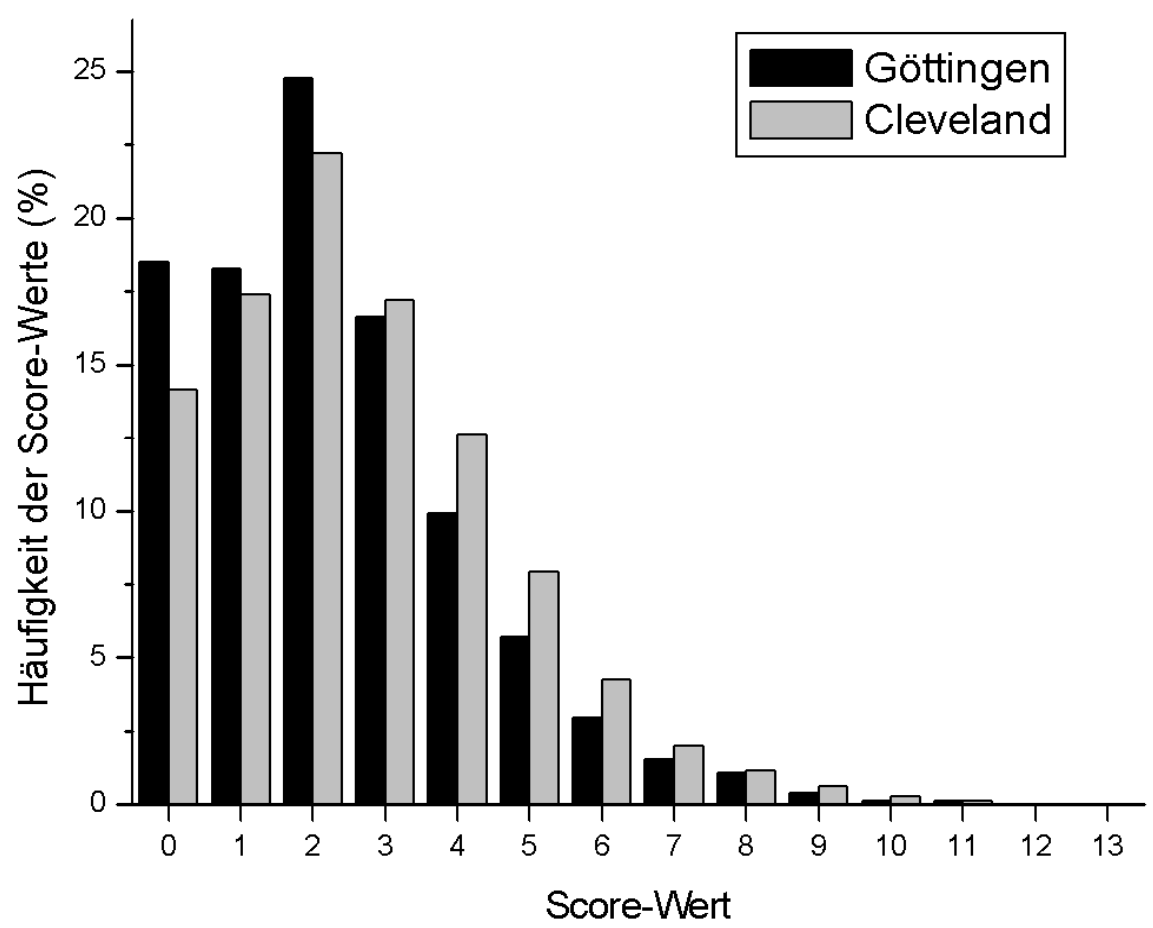

Abb. 8 : Verteilung der einzelnen Score-Werte

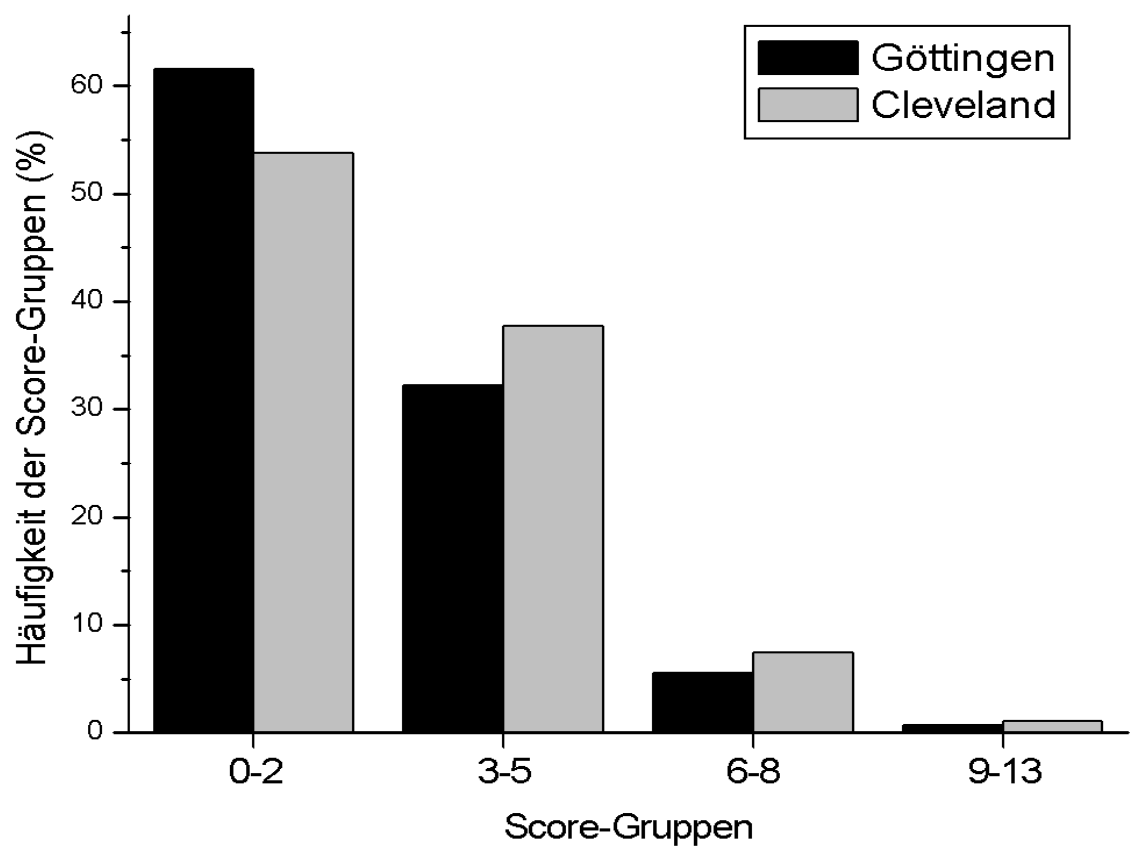

Abb. 9 : Häufigkeit der Risiko-Gruppen 


\subsection{Inzidenz des akuten Nierenversagens}

Für das Göttinger Kollektiv wurden die Inzidenzen des ANV sowohl für jeden individuellen Score-Wert als auch für die Score-Wert-Gruppen errechnet. Qualitativ ähnelten die Ergebnisse aus Göttingen denjenigen aus Cleveland dahingehend, dass mit zunehmendem Score-Wert auch der Anteil von Patienten mit akutem Nierenversagen stieg [s.Tab. 11, s.Abb. 10]. Dagegen lagen die absoluten Inzidenzen für ein ANV sowohl für die einzelnen ScoreWerte als auch innerhalb der Score-Wert-Gruppen in Göttingen deutlich höher als im Kollektiv von Cleveland. So lag bei dem niedrigsten Score-Wert von null Punkten der Anteil an Patienten im Göttinger Kollektiv mit akutem Nierenversagen bei 6,22 \% [Cleveland 0,05\%, 95\%-KI: 0-0,26\%]. Bei Patienten mit dem am häufigsten erreichten Score-Wert „Zwei“ betrug im Göttinger Kollektiv die Inzidenz des ANV 7,4\% [Cleveland 0,71\%, 95\%$\mathrm{KI}: 0,46-1,04 \%]$.

Analog zu den einzelnen Score-Werten nahm die Inzidenz des akuten Nierenversagens innerhalb der gebildeten Risikogruppen [0-2, 3-5, 6-8, 9-13] zu [s.Tab. 12, s.Abb. 11]. Auch in diesen Gruppen lagen die Inzidenzen des ANV in Göttingen deutlich höher als in Cleveland:

So trat ein akutes Nierenversagen in der ersten Risikoscoregruppe mit den Score-Werten von null bis zwei in Göttingen bei einem Patientenanteil von 6,71 \% auf, in Cleveland bei einem Patientenanteil von 0,4\% [95\%-KI: 0,28-0,56\%]. Die Inzidenz des akuten Nierenversagens stieg in der nächsten Risikoscoregruppe [drei bis fünf] in Göttingen auf einen Patientenanteil von 12,72 \%. In Cleveland hatten dagegen 1,8 \% der Patienten in dieser Gruppe ein akutes Nierenversagen [95\%-KI: 1,5-2,2\%]. In der darauffolgenden Risikoscoregruppe von sechs bis acht stieg in Göttingen die ANV-Inzidenz auf 29,02 \% , in Cleveland lag die Inzidenz der gleichen Gruppe bei 7,8 \% [95\%-KI: 6,3-9,5\%]. Bei den Score-Werten von neun bis dreizehn, die die letzte Risikoscoregruppe bildeten, waren im Göttinger Kollektiv 35 \% der Patienten von einem akuten Nierenversagen betroffen und im Kollektiv von Cleveland 21,5\% der Patienten [95\%-KI: 15,1-29,1\%].

Zusammenfassend ist in beiden Kollektiven zu sehen, dass zum einen mit zunehmendem Score-Wert die Inzidenz des ANV steigt. Zum anderen liegt die Inzidenz des akuten Nierenversagens in Göttingen sowohl innerhalb der einzelnen Score-Werte [0-11] als auch in 
den Risikoscore-Gruppen [0-2, 3-5, 6-8, 9-13] außerhalb der von Thakar prognostizierten 95\%-Konfidenzintervalle und ist somit signifikant höher als in Cleveland.

Tab.11 : Einzelne Score-Werte und Inzidenz des ANV

\begin{tabular}{|c|c|c|c|c|c|}
\hline & \multicolumn{2}{|l|}{$\begin{array}{l}\text { Göttingen } \\
\text { Häufigkeit des ANV }\end{array}$} & \multicolumn{2}{l|}{$\begin{array}{l}\text { Cleveland } \\
\text { Häufigkeit des ANV }\end{array}$} & $95 \%$ KI \\
\hline Score Punkte & $\mathrm{N}$ & $\%$ & $\mathrm{~N}$ & $\%$ & \\
\hline 0 & 466 & 6,22 & 2123 & 0,05 & $0-0,26$ \\
1 & 669 & 6,28 & 2760 & 0,29 & $0,13-0,57$ \\
2 & 757 & 7,40 & 3533 & 0,71 & $0,46-1,04$ \\
3 & 614 & 10,26 & 2949 & 1,19 & $0,83-1,65$ \\
4 & 451 & 11,97 & 1896 & 2,06 & $1,47-2,8$ \\
5 & 256 & 19,92 & 1252 & 3,04 & $2,16-4,14$ \\
6 & 140 & 24,29 & 685 & 6,42 & $4,71-8,53$ \\
7 & 74 & 31,08 & 323 & 9,60 & $6,67-13,15$ \\
8 & 41 & 41,46 & 173 & 9,83 & $5,83-15,27$ \\
9 & 26 & 26,92 & 82 & 21,95 & $13,56-32,46$ \\
10 & 11 & 54,55 & 40 & 12,50 & $4,19-26,8$ \\
11 & 3 & 33,33 & 14 & 21,43 & $4,66-50,08$ \\
12 & 0 & - & 7 & 57,14 & $18,41-90,1$ \\
13 & 0 & - & 1 & 100,00 & $2,5-100$ \\
\hline
\end{tabular}

Tab.12 : Risiko-Gruppen und Inzidenz des ANV

\begin{tabular}{|c|c|c|c|c|c|}
\hline & \multicolumn{2}{|l|}{$\begin{array}{l}\text { Göttingen } \\
\text { Häufigkeit des ANV }\end{array}$} & \multicolumn{2}{l|}{$\begin{array}{l}\text { Cleveland } \\
\text { Häufigkeit des ANV }\end{array}$} & $95 \%$ KI \\
\hline Risiko-Gruppen & $\mathrm{N}$ & $\%$ & $\mathrm{~N}$ & $\%$ & \\
\hline $0-2$ & 1892 & 6,71 & 8416 & 0,4 & $0,28-0,56$ \\
$3-5$ & 1321 & 12,72 & 6097 & 1,8 & $1,5-2,2$ \\
$6-8$ & 255 & 29,02 & 1181 & 7,8 & $6,3-9,5$ \\
$9-13$ & 40 & 35 & 144 & 21,5 & $15,1-29,1$ \\
\hline
\end{tabular}




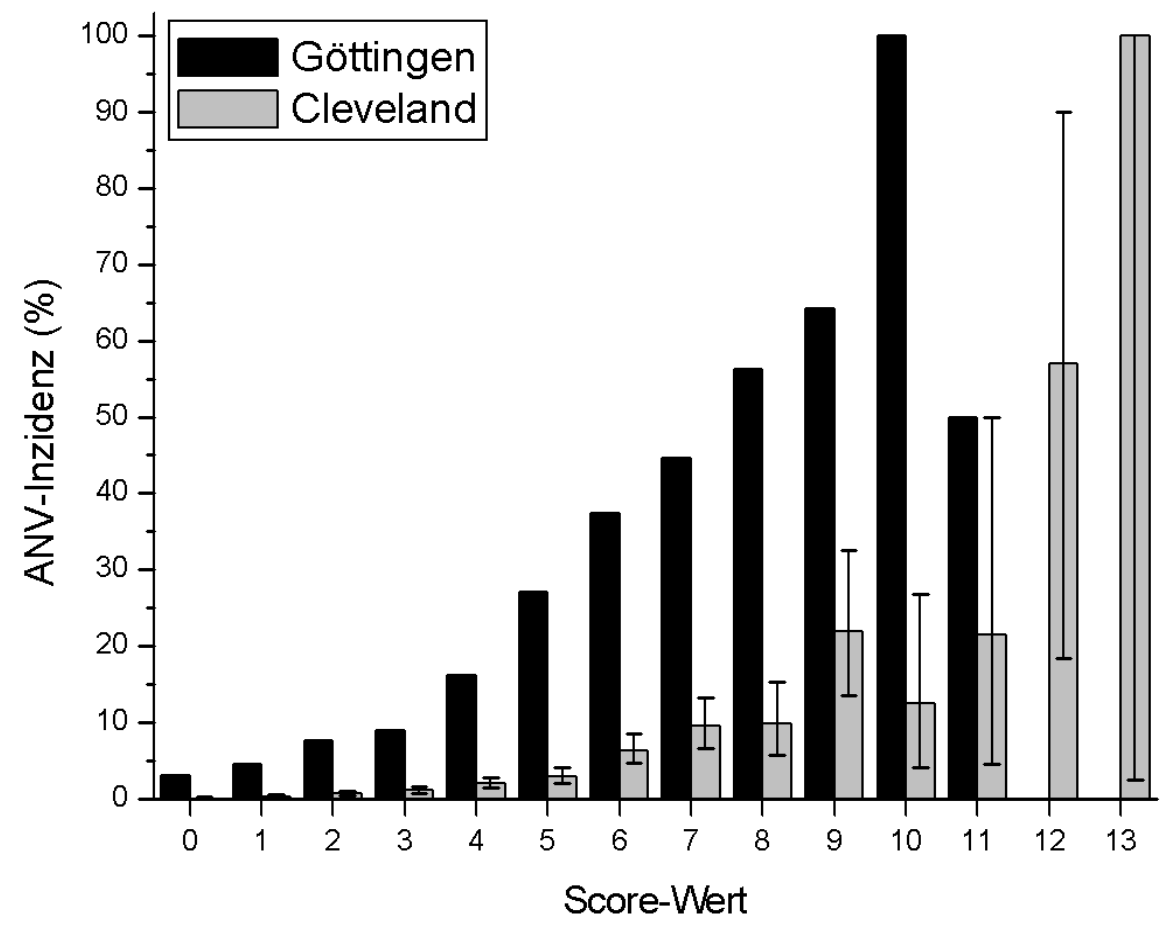

Abb.10 : Inzidenz des ANV in den einzelnen Score-Werten

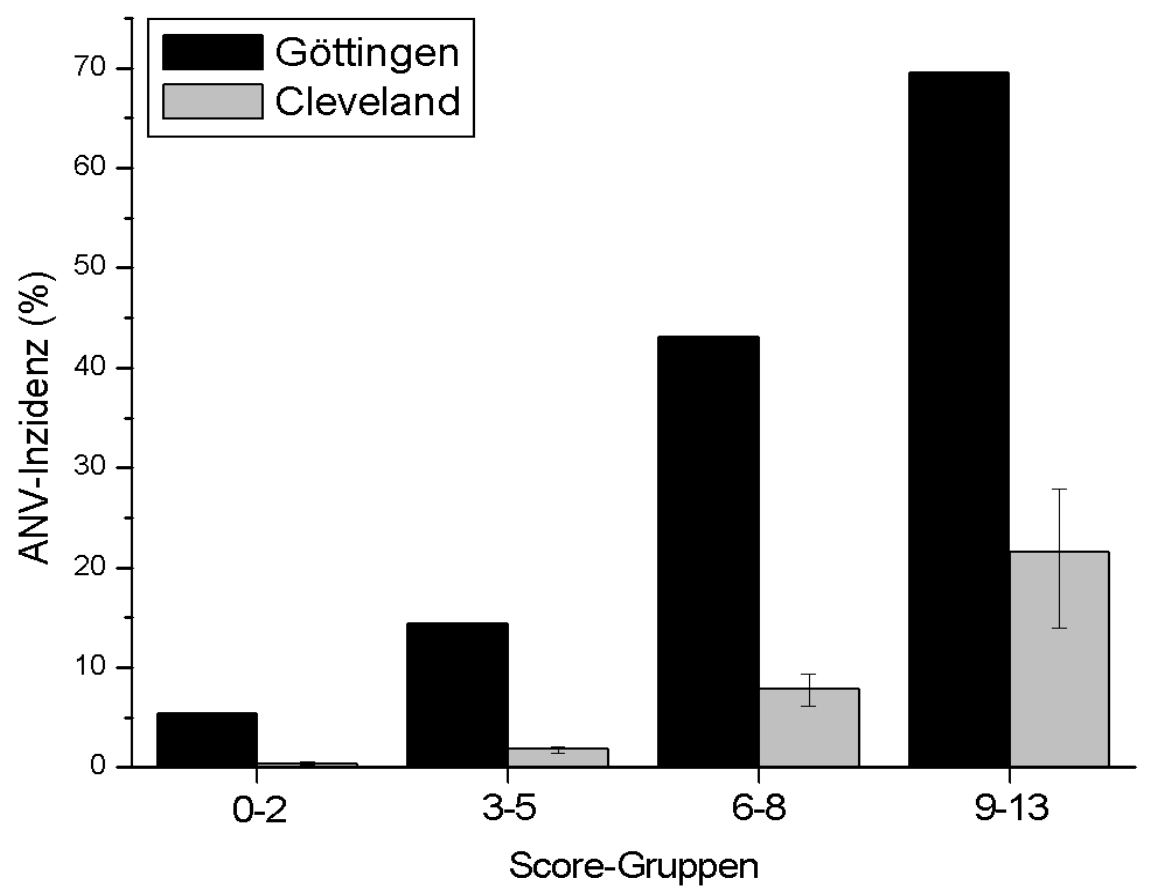

Abb.11 : Inzidenz des ANV in den Risiko-Gruppen 


\subsection{Sensitivität und Spezifität des Original-Scores}

Bei Anwendung des Original-Scores am Göttinger Kollektiv betrug die Fläche unter der Receiver-operating-characteristic-Kurve [AUC] 0,662. Das Konfidenzintervall erstreckte sich von 0,646 - 0,678. Somit war die diagnostische Aussagekraft geringer als im Validierungskollektiv aus Cleveland, bei dem ein AUC-Wert von 0,82 [95\%-KI: 0,80 $0,85 \%$ ] erreicht wurde [s.Abb. 12].
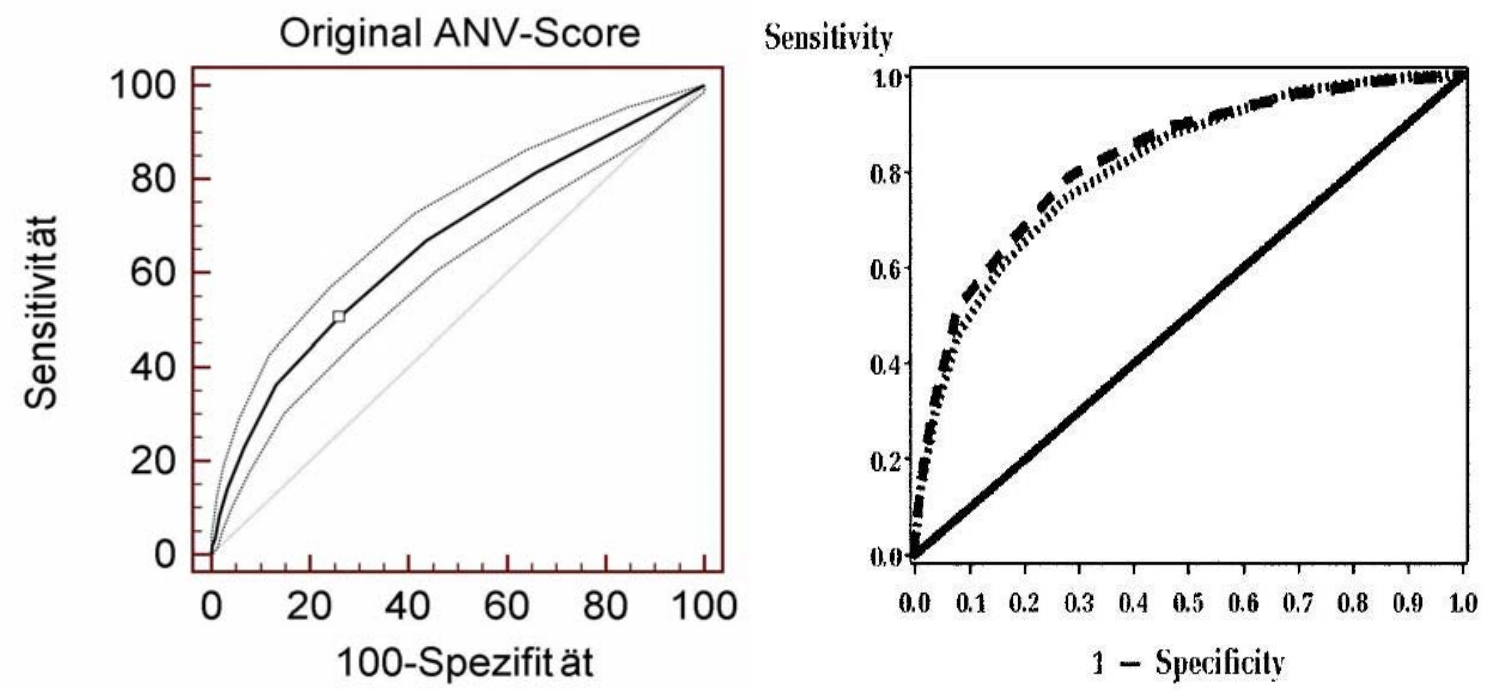

Abb.12 : Gegenüberstellung ROC-Kurve angewandt am Göttinger Kollektiv [links] mit der ROC-Kurve des Original-Thakar-Scores [rechts]

\subsection{Analyse der Risikofaktoren im Göttinger Kollektiv}

\subsubsection{Monovariate Analyse}

Bei der monovariaten Analyse zeigten folgende Faktoren eine unterschiedliche Verteilung in den Patientengruppen mit bzw. ohne akutes Nierenversagen [s. Tab. 13, 14]:

- Noteingriff $[\mathrm{p}<0,0001]$

- Insulinpflichtiger Diabetes mellitus [ $p<0,0001$ ]

- Zerebrovaskuläre Erkrankung [ p =0,0005 ] 
- Präoperativer Gebrauch einer IABP $[\mathrm{p}=0,001]$

- Ejektionsfraktion $<35 \%$ [ p = 0,004]

- $\operatorname{Re}-O P[p=0,035$ ]

- Präoperatives Serum-Kreatinin $[\mathrm{p}<0,001]$

Im Göttinger Kollektiv waren somit nicht signifikant unterschiedlich verteilt:

- Periphere Gefäßerkrankung [ $p=0,15$ ]

- $\operatorname{COPD}[\mathrm{p}=0,22$ ]

- Herzinsuffizienz [ $\mathrm{p}=0,27$ ]

- $\quad$ Art der OP [ p =0,78 ]

- $\quad$ Alter $[\mathrm{p}=0,068]$ 
Tab.13 : Vergleich monovariate Analyse der kategorischen Risikofaktoren für das ANV

\begin{tabular}{|c|c|c|c|c|c|c|}
\hline Risikofaktor [N = 3508] & $\begin{array}{l}\text { ANV } \\
{[\mathrm{N}=383]}\end{array}$ & & $\begin{array}{l}\text { Kein ANV } \\
{[N=3125]}\end{array}$ & & $\begin{array}{c}\text { P-Wert } \\
\text { Göttingen }\end{array}$ & $\begin{array}{c}\text { P-Wert } \\
\text { Cleveland }\end{array}$ \\
\hline \begin{tabular}{|l} 
Not-Eingriff \\
\\
$\qquad \begin{array}{l}\text { ja }[\mathrm{N}=334] \\
\text { nein }[\mathrm{N}=3174]\end{array}$
\end{tabular} & $\begin{array}{c}63 \\
320\end{array}$ & $\begin{array}{l}(16,4 \%) \\
(83,6 \%)\end{array}$ & $\begin{array}{c}271 \\
2854\end{array}$ & $\begin{array}{l}(8,7 \%) \\
(91,3 \%)\end{array}$ & $<0,0001$ & $<0,001$ \\
\hline $\begin{array}{l}\text { Diabetes mellitus } \\
\qquad \begin{array}{l}\text { IDDM [N }=503] \\
\text { NIDDM [N = 441] } \\
\text { kein D.m. [N=2564] }\end{array}\end{array}$ & $\begin{array}{c}85 \\
53 \\
245\end{array}$ & $\begin{array}{l}(22,2 \%) \\
(13,8 \%) \\
(64, \%)\end{array}$ & $\begin{array}{c}418 \\
388 \\
2319\end{array}$ & $\begin{array}{l}(13,4 \%) \\
(12,4 \%) \\
(74,2 \%)\end{array}$ & $<0,0001$ & $<0,001$ \\
\hline $\begin{array}{c}\text { Zerebrovaskuläre Erkrankung } \\
\text { ja [N=441] } \\
\text { nein }[\mathrm{N}=3067]\end{array}$ & $\begin{array}{c}70 \\
313\end{array}$ & $\begin{array}{l}(18,3 \%) \\
(81,7 \%)\end{array}$ & $\begin{array}{c}371 \\
2754\end{array}$ & $\begin{array}{l}(11,9 \%) \\
(88,1 \%)\end{array}$ & 0,0005 & $<0,001$ \\
\hline $\begin{array}{c}\text { Präoperative Anlage einer IABP } \\
\text { ja }[\mathrm{N}=38] \\
\text { nein }[\mathrm{N}=3470]\end{array}$ & $\begin{array}{c}12 \\
371\end{array}$ & $\begin{array}{l}(3,1 \%) \\
(96,9 \%)\end{array}$ & $\begin{array}{c}26 \\
3099\end{array}$ & $\begin{array}{l}(0,8 \%) \\
(99,2 \%)\end{array}$ & 0,001 & $<0,001$ \\
\hline $\begin{array}{c}\text { Ejektionsfraktion }<35 \% \\
\qquad \begin{array}{c}\text { ja }[\mathrm{N}=432] \\
\text { nein }[\mathrm{N}=3076]\end{array}\end{array}$ & $\begin{array}{c}65 \\
318\end{array}$ & $\begin{array}{l}(17, \%) \\
(83, \%)\end{array}$ & $\begin{array}{c}367 \\
2758\end{array}$ & $\begin{array}{l}(11,7 \%) \\
(88,3 \%)\end{array}$ & 0,0043 & $<0,001$ \\
\hline $\begin{array}{l}\text { ja }[N=244] \\
\text { nein }[N=3264]\end{array}$ & $\begin{array}{c}37 \\
346\end{array}$ & $\begin{array}{l}(9,7 \%) \\
(90,3 \%)\end{array}$ & $\begin{array}{c}207 \\
2918\end{array}$ & $\begin{array}{l}(6,6 \%) \\
(93,4 \%)\end{array}$ & 0,0359 & $<0,001$ \\
\hline $\begin{array}{c}\text { Periphere vaskuläre Erkrankung } \\
\text { ja }[\mathrm{N}=312] \\
\text { nein }[\mathrm{N}=3196]\end{array}$ & $\begin{array}{c}42 \\
341\end{array}$ & $\begin{array}{l}(11, \%) \\
(89, \%)\end{array}$ & $\begin{array}{c}270 \\
2855\end{array}$ & $\begin{array}{l}(8,6 \%) \\
(91,4 \%)\end{array}$ & 0,1573 & $<0,001$ \\
\hline $\begin{array}{l}\text { ja }[N=491] \\
\text { nein }[N=3017]\end{array}$ & $\begin{array}{c}62 \\
321\end{array}$ & $\begin{array}{l}(16,2 \%) \\
(83,8 \%)\end{array}$ & $\begin{array}{c}429 \\
2696\end{array}$ & $\begin{array}{l}(13,7 \%) \\
(86,3 \%)\end{array}$ & 0,2181 & $<0,001$ \\
\hline $\begin{array}{l}\text { Herzinsuffizienz } \\
\qquad \begin{array}{l}\text { ja }[\mathrm{N}=577] \\
\text { nein }[\mathrm{N}=2931]\end{array}\end{array}$ & $\begin{array}{c}71 \\
312\end{array}$ & $\begin{array}{l}(18,5 \%) \\
(81,5 \%)\end{array}$ & $\begin{array}{c}506 \\
2619\end{array}$ & $\begin{array}{l}(16,2 \%) \\
(83,8 \%)\end{array}$ & 0,2732 & $<0,001$ \\
\hline \begin{tabular}{|l} 
Art des kardiochirurg. Eingriffs \\
$\qquad \begin{array}{l}\text { Bypass [N = 1929] } \\
\text { Klappenersatz } \\
\text { Bypass+Klappe [N =609] } \\
\text { andere OP [N = 331] }\end{array}$
\end{tabular} & $\begin{array}{c}204 \\
68 \\
71 \\
40\end{array}$ & $\begin{array}{l}(53,3 \%) \\
(17,8 \%) \\
(18,5 \%) \\
(10,4 \%)\end{array}$ & $\begin{array}{l}1725 \\
571 \\
538 \\
291\end{array}$ & $\begin{array}{l}(55,2 \%) \\
(18,3 \%) \\
(17,2 \%) \\
(9,3 \%)\end{array}$ & 0,7796 & $<0,001$ \\
\hline
\end{tabular}


Tab.14 : Vergleich univariate Analyse der kontinuierlichen Risikofaktoren für das ANV

\begin{tabular}{|l|l|l|c|c|}
\hline Risikofaktor [N = 3508] & $\begin{array}{l}\text { ANV } \\
{[N=383]}\end{array}$ & $\begin{array}{l}\text { kein ANV } \\
{[N=3125]}\end{array}$ & $\begin{array}{c}\text { P-Wert } \\
\text { Göttingen }\end{array}$ & $\begin{array}{c}\text { P-Wert } \\
\text { Cleveland }\end{array}$ \\
\hline $\begin{array}{l}\text { Präoperatives Kreatinin [mg/dl] } \\
\text { MW } \pm S D\end{array}$ & $1,54 \pm 1,40$ & $1,11 \pm 0,73$ & $<0,001$ & $<0,001$ \\
\hline $\begin{array}{l}\text { Alter [Jahre] } \\
\text { MW } \pm S D\end{array}$ & $68,8 \pm 12,5$ & $64,8 \pm 13,7$ & 0,068 & $<0,001$ \\
\hline
\end{tabular}

\subsubsection{Multivariate Analyse der unterschiedlich verteilten Risikofaktoren}

Die signifikant unterschiedlich verteilten Risikofaktoren wurden mittels logistischer Regression auf ihren unabhängigen Einfluss auf die Entstehung eines akuten Nierenversagens überprüft [s. Tab. 15]. Zusätzlich konnte anhand der Odds Ratios eine quantitative Gewichtung der einzelnen Risikofaktoren für das Risiko eines akuten Nierenversagens vorgenommen werden.

Einen signifikanten unabhängigen Einfluss auf das Ereignis „Akutes Nierenversagen“ hatten:

- Präoperatives Serum-Kreatinin $>2 \mathrm{mg} / \mathrm{dl}[\mathrm{p}<0,001]$

- Präoperatives Serum-Kreatinin 1,2 to $2 \mathrm{mg} / \mathrm{dl}[\mathrm{p}<0,001]$

- Präoperative Anlage einer IABP [ $\mathrm{p}<0,039$ ]

- Noteingriff $[\mathrm{p}<0,001]$

- Insulinpflichtiger Diabetes mellitus [ $p<0,001]$

- Weibliches Geschlecht $[\mathrm{p}<0,013]$

- Zerebrovaskuläre Erkrankung [ $\mathrm{p}<0,004$ ]

Keinen signifikanten unabhängigen Einfluss auf das Ereignis „Akutes Nierenversagen“ hatten:

- Nicht-insulinpflichtiger Diabetes mellitus [NIDDM]

- Linksventrikuläre Ejektionsfraktion $<35 \%$

- Re-Eingriff 
Tab.15 : Vergleich multivariate Analyse der Thakar-definierten ANV Risikofaktoren

\begin{tabular}{|c|c|c|c|c|c|c|}
\hline \multirow[b]{2}{*}{ Risikofaktor: } & \multicolumn{3}{|c|}{ Goettingen } & \multicolumn{3}{|c|}{ Thakar 2005} \\
\hline & Regressionskoeffizient & P-Wert & Scorepunkte & Regressionskoeffizient & P-Wert & Scorepunkte \\
\hline Präop. Krea. $\geq 2,1 \mathrm{mg} / \mathrm{dl}$ & 1,851 & $<0,001$ & 4 & 2,66 & $<0,001$ & 5 \\
\hline Präop.Krea. 1,2 to $<2,1 \mathrm{mg} / \mathrm{dl}$ & 0,7912 & $<0,001$ & 2 & 0,92 & $<0,001$ & 2 \\
\hline Präop. Anlage einer IABP & 0,7857 & 0,0393 & 2 & 1,08 & $<0,001$ & 2 \\
\hline Noteingriff & 0,6142 & $<0,001$ & 1 & 1,13 & $<0,001$ & 2 \\
\hline IDDM & 0,5741 & $<0,001$ & 1 & 0,4 & 0,026 & 1 \\
\hline Weiblich & 0,2992 & 0,0134 & 1 & 0,48 & $<0,001$ & 1 \\
\hline Cerebrovaskuläre Erkrankung & 0,4218 & 0,0044 & 1 & \multirow{2}{*}{\multicolumn{2}{|c|}{$\begin{array}{l}\text { (nach log. Regression ausgeschlossen) } \\
\text { (nach log. Regression ausgeschlossen) }\end{array}$}} & - \\
\hline NIDDM & \multirow{6}{*}{\multicolumn{2}{|c|}{$\begin{array}{l}\text { (nach log. Regression ausgeschlossen) } \\
\text { (nicht eingeschlossen in log. Regression) } \\
\text { (nach log. Regression ausgeschlossen) } \\
\text { (nicht eingeschlossen in log. Regression) } \\
\text { (nach log. Regression ausgeschlossen) } \\
\text { (nicht eingeschlossen in log. Regression) }\end{array}$}} & - & & & - \\
\hline Herzinsuffizienz & & & - & 0,48 & $<0,001$ & 1 \\
\hline LV-Ejektionfraktion < 35\% & & & - & 0,39 & 0,016 & 1 \\
\hline COPD & & & - & 0,7 & $<0,001$ & 1 \\
\hline Re-Eingriff & & & - & 0,54 & $<0,001$ & 1 \\
\hline OP-Art: & & & - & & & \\
\hline nur Klappe & & & - & 0,45 & 0,013 & 1 \\
\hline Bypass + Klappe & & & - & 0,86 & $<0,001$ & 2 \\
\hline anderer kardiochirurg.OP & & & - & 1,02 & & 2 \\
\hline
\end{tabular}

\subsection{Anwendung des „modifizierten“ Scores im Göttinger Kollektiv}

In Göttingen wurden drei der insgesamt zehn kontinuierlichen Risikofaktoren nicht mit in die multivariate Analyse einbezogen. In der anschließenden logistischen Regression konnte für weitere drei Risikofaktoren kein signifikanter Einfluss auf das Endergebnis eines ANV gezeigt werden. Daraus resultierte, dass für das Göttinger Kollektiv ein modifizierter Score aus insgesamt sieben Risikofaktoren und den korrespondierenden Scorepunkten erstellt wurde.

Bei der Anwendung dieses modifizierten Scores am Göttinger Kollektiv resultierte eine Fläche unter der Receiver-operating-characteristic-Kurve mit einem Wert von 0,671 [95\%KI: 0,655 - 0,687]. Demgegenüber betrug der AUC-Wert bei der Verwendung des OriginalScores von Thakar am Göttinger Kollektiv 0,662 [Konfidenzintervall von 0,646 bis 0,678] [s. Abb. 13]. Der Unterschied zwischen beiden AUC-Werten der ROC-Kurve ist statistisch nicht signifikant. Sensitivität und Spezifität des Scores konnten somit durch Neu-Adjustierung der Risikofaktoren nicht verbessert werden. 

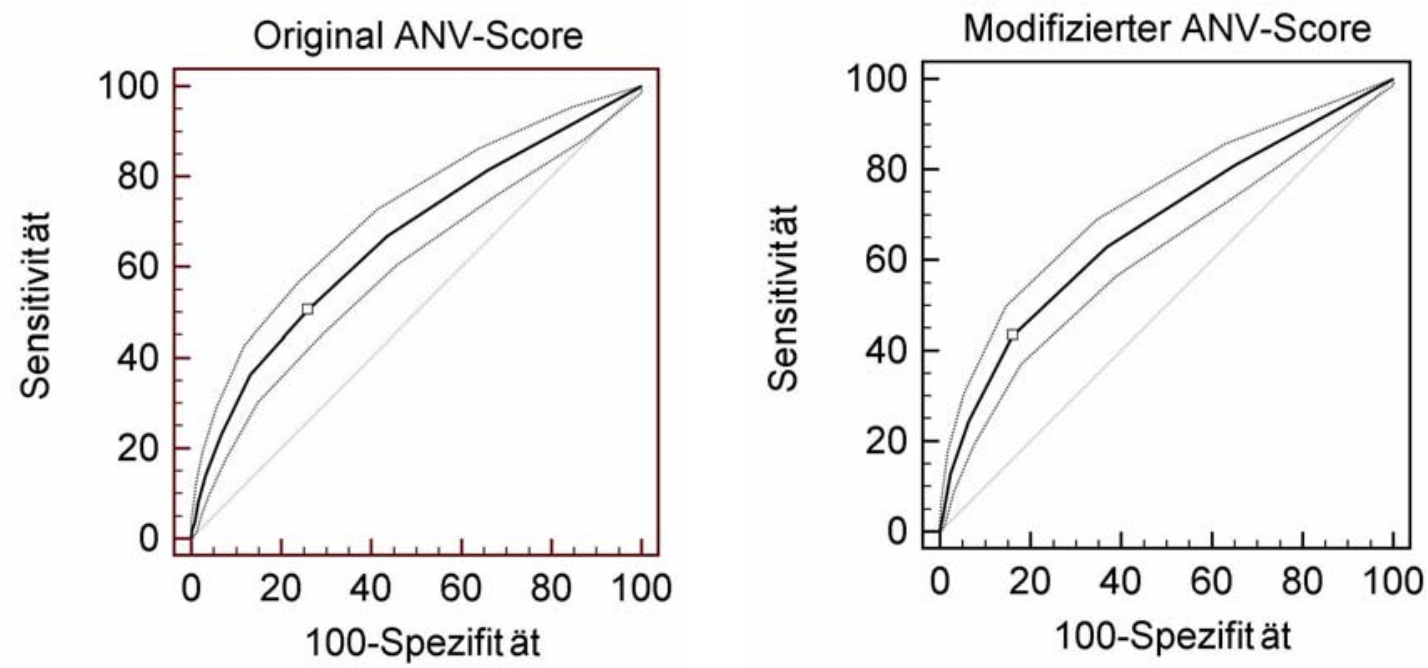

Abb.13 : ROC-Kurve des Original-Scores angewandt am Göttinger Kollektiv [links] und ROC-Kurve des modifizierten Scores [rechts] 


\section{Diskussion}

\subsection{Fragestellung}

\subsubsection{Bedeutung des postoperativen akuten Nierenversagens}

Das akute Nierenversagen hat bei kardiochirurgischen Patienten nicht nur eine sehr hohe Inzidenz, es führt auch zu einer erheblichen Steigerung der Mortalität (Praught und Shlipak 2005; Rosner und Okusa 2006) sowie zu einem schlechteren Outcome (Ryckwaert et al. 2002; Lassnigg et al. 2004). Da nicht nur die Anzahl kardiochirurgischer Eingriffe zunimmt, diese Patienten ein immer breiteres Spektrum an Vorerkrankungen aufweisen, gewinnt das ANV zunehmend an Bedeutung. Aus diesem Grund beschäftigen sich viele klinische Studien mit der Entstehung, Erkennung und Therapie eines akuten Nierenversagens.

\subsubsection{Bedeutung der frühzeitigen Erkennung eines ANV}

Die frühzeitige Erkennung eines ANV ist deshalb von großer Bedeutung, weil diverse prophylaktische und therapeutische Strategien existieren, mit denen Entstehung bzw. Auswirkungen des ANV reduziert werden können. Die wichtigste präoperative Strategie besteht in der ausreichenden Hydrierung des Patienten, die jedoch noch kontrovers diskutiert wird. Dagegen konnte für bestimmte intraoperative Maßnahmen ein günstiger Effekt auf die Entstehung des ANV gezeigt werden. Hierzu zählen z.B. „Off-Pump-Verfahren“ gegenüber dem herkömmlichen Einsatz der Herz-Lungen-Maschine (Stallwood et al. 2004), die Einhaltung kurzer Zeiten extrakorporaler Zirkulation, ein Hämatokrit zwischen 21-25\% und ein optimales Sauerstoffangebot (Karkouti et al. 2005; Ranucci et al. 2005; Taniguchi et al. 2007). Darüber hinaus kann der Enstehung eines ANV auch intraoperativ durch die Gabe von Pharmaka wie N-Acetylcystein, Diltiazem (Bergman et al. 2002) oder dem selektiven Dopamin-1-Rezeptor-Agonisten Fenoldopam entgegengewirkt werden (Barr und Kolodner 2008; Sisillo et al. 2008). Zu den postoperativen Strategien zur Prophylaxe eines akuten Nierenversagens zählen die Optimierung der Hämodynamik und des Flüssigkeitshaushaltes (Bellomo et al. 2005; Kellum et al. 2005; Jones und Lee 2007) sowie die möglichst restriktive Indikationsstellung für den Einsatz nephrotoxischer Substanzen [Kontrastmittel, 
Aminoglykosid-Antibiotika). Darüber hinaus konnte gezeigt werden, dass ein frühzeitiger Beginn einer Nierenersatztherapie mit einem verbesserten Outcome des Patienten vergesellschaftet war (Demirkilic et al. 2004; Elahi et al. 2004).

Eine optimale Fokussierung all dieser Maßnahmen macht es jedoch erforderlich, Patienten mit einem hohen ANV-Risiko so frühzeitig als möglich zu identifizieren.

\subsubsection{Limitationen klinisch gebräuchlicher Nierenfunktionsparameter}

Die in der klinischen Praxis gebräuchlichsten Nierenfunktionsparameter basieren auf dem Serum-Kreatinin. Dieser Parameter ist jedoch nicht nur mit dem Nachteil behaftet, dass ein Anstieg des Serum-Kreatinins mit einer deutlich zeitlichen Latenz erfolgt, sondern auch erst bei einer erheblichen Reduktion der GFR zu beobachten ist (Chiou und Hsu 1975).

Um das akute Nierenversagen trotzdem möglichst früh postoperativ zu erkennen, wurden auch Studien mit neuartigen Parametern der tubulären und glomerulären Nierenfunktion durchgeführt, in denen sich NGAL, Cystatin C und al-Mikroglobulin als geeignet erwiesen, eine akute Nierenschädigung bereits früh postoperativ nachzuweisen (Heise et al. 2010; Perry et al. 2010). Obwohl die Parameter wie z.B. NGAL sofort nach dem Nierenschaden signifikant erhöht sind und so die Optimierung der postoperativen Therapie erlauben, zeigen sie jedoch eine bereits stattgehabte Schädigung an und sind daher für die prä- und intraoperative Planung nephroprotektiver Maßnahmen ungeeignet.

\subsubsection{Entwicklung und Stellenwert prognostischer Scores}

Aus den genannten Gründen wurden prognostische Scores entwickelt, mit denen die Wahrscheinlichkeit eines kardiochirurgisch-assoziierten ANV abgeschätzt werden kann. Da die Entstehung eines ANV nicht nur von präoperativen, sondern auch intra- und postoperativen Risikofaktoren begünstigt wird, können grundsätzlich Risikofaktoren dieser drei Kategorien in einen Score einfließen. Die bislang entwickelten und etablierten Scores basieren jedoch weitestgehend auf präoperativen Risikofaktoren (Mehta et al. 2006; Palomba et al. 2007; Wijeysundera et al. 2007). Diese Begrenzung ist zwar mit dem Nachteil behaftet, dass der z.T. erhebliche Einfluss von intraoperativen und postoperativen Ereignissen nicht mit einbezogen wird, was möglicherweise die Präzision der Voraussage einschränken kann. Jedoch erlaubt die bereits präoperative Einschätzung des ANV-Risikos die optimale 
Ausschöpfung aller intra- und postoperativen Maßnahmen zur Vermeidung einer Nierenschädigung. Die o.g. Scores wurden jedoch an monozentrischen Patientenkollektiven entwickelt und validiert, weshalb ihre Aussagekraft an anderen Patientenkollektiven noch untersucht werden muss.

\subsubsection{Auswahl des Scores von Thakar}

Das Ziel der vorliegenden Studie war, die prognostische Aussagekraft des Thakar-Scores an kardiochirurgischen Patienten der Universitätsklinik Göttingen zu überprüfen. Da zum Zeitpunkt des Beginns der vorliegenden Untersuchung lediglich der Thakar-Score publiziert war, begrenzte sich die Studie auf die Validierung dieses prognostischen Systems. Die Vorteile dieses Scores bestehen zum einen darin, dass er an einem sehr großen Patientenkollektiv entwickelt wurde, woraus eine hohe Genauigkeit der Ergebnisse resultiert. Zum anderen basiert dieser Score auf ausschließlich präoperativen Risikofaktoren, was die maximal frühzeitige Einschätzung des Patientenrisikos erlaubt. Ein weiterer Vorteil des Thakar-Scores ist, dass das Merkmal „Re-Eingriff“ als Surrogat-Parameter für die Dauer der HLM, dem wichtigsten intraoperativen Risikofaktor, verwendet wird, da Wiederholungseingriffe in der Regel mit längeren Zeiten an der HLM einhergehen (Thakar et al. 2005). Demgegenüber wiesen die Autoren jedoch einschränkend in ihrer Arbeit darauf hin, dass die Übertragbarkeit ihres Scores auf andere Patientenkollektive noch überprüft werden muss.

\subsection{Größe des Patientenkollektivs, Datenqualität}

Grundsätzlich ist bei statistischen Fragestellungen eine möglichst große Anzahl ausgewerteter Patienten anzustreben, um auch für gering ausgeprägte Unterschiede untersuchter Merkmale das erforderliche statistische Signifikanzniveau zu erreichen. Das Göttinger Patientendatenmanagementsystem GISI wurde jedoch häufig modifiziert und somit an aktuelle Gegebenheiten angepasst. Dadurch nahm die Inhomogenität der Datensätze zu, je größer der Auswertungszeitraum gewählt wurde. Bei der Größe des Patientenkollektivs musste somit ein Kompromiss zwischen Umfang und Homogenität des zugrunde liegenden Datensatzes gefunden werden. 
In Göttingen werden jährlich ca.1000 Patienten unter Einsatz der Herz-Lungen-Maschine einem kardiochirurgischem Eingriff unterzogen. Aus Sicht der Vollständigkeit der Daten schien eine Auswertung der Datensätze der Jahre 2002-2005 geeignet zu sein. Die hieraus resultierende Größe des Kollektivs von 3000 - 4000 Patienten stellte einen geeigneten Kompromiss zwischen dem Stichprobenumfang und der Homogenität der Daten dar. In diese Überlegung wurde ebenfalls mit einbezogen, dass ein bestimmter Anteil an Patientendatensätzen aufgrund von Unvollständigkeit nicht in die Auswertung einbezogen werden konnte, so dass die Anzahl der tatsächlich ausgewerteten Datensätze etwas niedriger lag, als der zunächst abgeschätzte Umfang.

Die Datenqualität war durch zwei grundsätzliche Einschränkungen limitiert. Zum einen musste das Vorhandensein bestimmter Risikofaktoren anhand von Freitexteingaben beurteilt werden, die einen gewissen Interpretationsspielraum zuließen wie z.B. der Risikofaktor Herzinsuffizienz. In vielen Fällen war dieser Risikofaktor zwar nicht explizit dokumentiert, obwohl anamnestische Angaben wie z.B. Belastungsdyspnoe oder Unterschenkelödeme auf eine Herzinsuffizienz hinwiesen. In diesen Fällen war eine sorgfältige Interpretation des Auswerters erforderlich. Zum anderen enthielt eine Vielzahl der Datensätze zu bestimmten Risikofaktoren keinerlei [direkte oder indirekte] anamnestische Angaben. In diesen Fällen musste das Vorhandensein der betreffenden Risikofaktoren aus anderen Bestandteilen des Datensatzes wie z.B. Vormedikation, Angaben zur EF ermittelt werden. Beispiele hierfür sind COPD oder Diabetes mellitus, die anhand bestimmter Vormedikationen identifiziert werden konnten. Auch hierfür war die Interpretation des Auswerters erforderlich.

Da diese Einschränkungen auf die grundsätzliche Strukur des Patientendatenmanagementsystems GISI zurückzuführen waren, war ein bestimmtes Maß an Subjektivität bei der Auswertung der Datensätze systembedingt nicht zu umgehen. Um aber interpretationsbedingte Einflüsse möglichst gering zu halten, erfolgte die Zuordnung von Scorepunkten zu jedem einzelnen Datensatz durch ein und denselben Untersucher. 


\subsection{Ergebnisse}

\subsubsection{Validierung des Thakar-Scores am Göttinger Kollektiv}

Die prognostische Aussagekraft des Thakar-Scores war bei seiner Anwendung am Göttinger Kollektiv geringer ausgeprägt als im Validierungskollektiv aus Cleveland. Während Thakars AUC-Wert von 0,82 einer ,guten“ Trennschärfe entspricht, besagt der AUC-Wert von 0,662 bei der Anwendung am Göttinger Kollektiv lediglich eine „mäßige“ Sensitivität und Spezifität. Die Häufigkeiten der Score-Werte bzw. Scorewert-Gruppen waren in den Kollektiven von Göttingen und Cleveland qualitativ gleich verteilt. Somit ergaben sich keine Hinweise für die Annahme, dass diese reduzierte Trennschärfe auf relevante Unterschiede im Patientengut zurückzuführen ist. Dagegen bestand ein weiterer Unterschied zwischen den beiden Kollektiven darin, dass die Score-Werte in Göttingen zwischen null und elf Punkten lagen, während in Cleveland auch Score-Werte von zwölf und dreizehn erreicht wurden. Da Score-Werte über elf in Cleveland nur von sechs der 15.839 Patienten erreicht wurde, kommt diesem Unterschied nur eine untergeordnete Bedeutung zu. Als wahrscheinlichster Grund für die reduzierte prognostische Aussagekraft am Göttinger Kollektiv wurde andererseits die nicht immer gegebene Objektivität bei der Vergabe von Score-Punkten für einzelne Risikofaktoren angenommen [s. Kapitel 4.2. Größe des Patientenkollektivs, Datenqualität]. Andererseits stellt aber auch der Einsatz von Nierenersatzverfahren keine objektive Definition für das akute Nierenversagen dar, da die Indikation in vielen Fällen unterschiedlich restriktiv gefällt werden kann.

\subsubsection{Inzidenz des Akuten Nierenversagens}

Übereinstimmend mit den Daten aus Cleveland nimmt auch im Göttinger Kollektiv die Inzidenz des akuten Nierenversagens mit steigendem Score-Wert zu. Jedoch lag das ANV im Göttinger Kollektiv in allen Score-Bereichen deutlich außerhalb des von Thakar angegebenen 95\%-Konfidenzintervalls. Zu qualitativ gleichen Ergebnissen kam auch die Arbeitsgruppe von Candela-Toha et. al., die ebenfalls eine mangelhafte Kalibration des Thakar-Scores an ihrem Patientenkollektiv beobachteten (Candela-Toha et al. 2008).

Die wahrscheinlichste und naheliegendste Ursache für diese Unterschiede in den Ergebnissen ist, dass das akute Nierenversagen über den Einsatz von Dialyseverfahren definiert wurde. Da 
nur in wenigen klinischen Situationen eine absolute Indikation für den Beginn eines Nierenersatzverfahrens gegeben ist, ist deren Einsatz in der überwiegenden Mehrzahl der Fälle von lokalen Standards der jeweiligen Intensivstationen abhängig (Gibney et al. 2008). Diese uneinheitlichen, an verschiedene therapeutische Standards angelehnten Definitionen des ANV stellen ein allgemeines Problem nicht nur für den Vergleich wissenschaftlicher Studien, sondern auch unterschiedlicher Therapiestrategien dar (Yallop und Smith 2004). Aus diesem Grund wurden in den vergangenen Jahren maximal objektive Definitions- und Klassifikationssysteme für das akute Nierenversagen entwickelt wie z.B. die RIFLE-Kriterien (Bellomo et al. 2007) oder die daraus weiterentwickelte AKIN-Klassifikation (Bagshaw et al. 2008). Zum Zeitpunkt der Entwicklung des Thakar-Scores [2005] waren diese Klassifikationssysteme jedoch noch nicht etabliert. Da die vorliegende Untersuchung die Anwendbarkeit des Original Scores von Thakar untersuchen sollte, wurde auch der Endpunkt, d.h. die Definition des Akuten Nierenversagens, unverändert übernommen.

Die Verwendung der RIFLE bzw. AKIN-Kriterien für die Definition eines ANV könnte jedoch die Vergleichbarkeit und Objektivität zukünftiger klinischer Studien deutlich verbessern.

\subsubsection{Analyse der einzelnen Risikofaktoren und Modifikation des Original-Scores}

Nicht alle der von Thakar identifizierten Risikofaktoren waren im Göttinger Kollektiv zwischen den beiden Patientengruppen signifikant unterschiedlich verteilt, wobei einige Risikofaktoren wie z.B. Zerebrovaskuläre Erkrankungen das statistische Signifikanzniveau jedoch nur knapp verfehlten. Somit kann davon ausgegangen werden, dass diese Risikofaktoren in einem größeren Patientenkollektiv Unterschiede mit statistischer Signifikanz aufgewiesen hätten. $\mathrm{Zu}$ vergleichbaren Ergebnissen kam eine Studie von di Bella, in der von den 11 Risikofaktoren des Thakar Scores lediglich fünf Risikofaktoren in den beiden Patientengruppen signifikant unterschiedlich verteilt waren (Di Bella et al. 2007). Dagegen zeigte der Risikofaktor „Art des kardiochirurgischen Eingriffs“ in den Patientengruppen mit bzw. ohne ANV eine absolut identische Verteilung. Dies ist inbesondere deshalb von Bedeutung, da Angaben zur OP-Art nicht nur obligat, d.h. in jedem Datensatz vorhanden waren, sondern auch keinerlei Interpretation bedurften und daher maximal objektiv waren. Aus diesem Grund scheint die Art des operativen Eingriffs im Göttinger Kollektiv daher tatsächlich keinen Einfluss auf die Entstehung eines ANV zu haben. 
In der multivariaten Analyse mittels logistischer Regression konnte für drei der Risikofaktoren [Diabetes mellitus, LVEF, Re-Eingriff] kein unabhängiger Einfluss für die Entstehung eines postoperativen ANV gezeigt werden. Alle drei Risikofaktoren verfehlten jedoch nur knapp das statistische Signifikanzniveau, so dass auch hier angenommen werden kann, dass bei Auswertung eines größeren Patientenkollektivs ein unabhängiger Einfluss dieser Risikofaktoren nachweisbar gewesen wäre.

Durch die Modifikation des Scores konnten Sensitivität und Spezifität nur minimal gesteigert werden [AUC des Original Scores 0,662, AUC des modifizierten Scores 0,671]. Die Adjustierung der Gewichtung der einzelnen Risikofaktoren spielt somit eine untergeordnete Rolle für die prognostische Aussagekraft. Die niedrigeren AUC-Werte sowohl des OriginalScores als auch des modifizierten Scores bei der Anwendung im Göttinger Kollektiv scheinen somit auf zwei Ursachen zurückzuführen zu sein:

Wie bereits beschrieben, war die retrospektive Zuordnung von Risikofaktoren nicht immer vollständig objektiv und direkt möglich. Hieraus ergibt sich eine Unschärfe bei der Berechnung der individuellen Score-Werte, die zu einer Abnahme der diagnostischen Trennschärfe des Scores führen kann. Darüber hinaus konnte der Endpunkt dialysepflichtigen Nierenversagens zwar für alle Patienten objektiv beurteilt werden, jedoch unterliegt die Indikationsstellung zur Dialyse dem behandelnden Arzt und ist daher mit einem gewissen Maß an Subjektivität verbunden.

\subsection{Schlussfolgerung}

Der präoperativen Abschätzung des Risikos eines postoperativen akuten Nierenversagens nach kardiochirurgischen Eingriffen kommt eine große Bedeutung zu, da sie die Grundlage für die Indikationsstellung nephroprotektiver Behandlungsmaßnahmen darstellt. Obwohl mit zunehmendem Score-Wert auch eine Zunahme der ANV-Inzidenz zu beobachten war, erlaubte die Anwendung des Scores am Göttinger Kollektiv, gemessen an der Fläche unter der ROCKurve, jedoch nur eine weniger präzise Voraussage des ANV-Risikos als im Validierungskollektiv aus Cleveland. Auch die Adjustierung der einzelnen Risikofaktoren führte zu keiner relevanten Verbesserung der prognostischen Aussagekraft. 
Der Thakar-Score scheint somit grundsätzlich für die präoperative Abschätzung des ANVRisikos geeignet zu sein. Voraussetzung für die optimale Anwendung dieses Scores ist jedoch zum einen die maximal objektive [d.h. interpretationsfreie] Bewertung der Risikofaktoren jedes einzelnen Patienten. Zum anderen könnte darüber hinaus die Übertragbarkeit der Ergebnisse aus monozentrischen Analysen möglicherweise verbessert werden, indem auch der Endpunkt akuten Nierenversagens maximal objektiv definiert wird. Anstatt des von Thakar gewählten Kriteriums „Einsatz eines Nierenersatzverfahrens“ sollten die inzwischen etablierten RIFLE- oder AKIN-Kriterien zur Klassifikation einer akuten Nierenschädigung verwendet werden. 


\section{Zusammenfassung}

Der möglichst frühzeitigen, d.h. präoperativen, Abschätzung des Risikos für die Entstehung eines postoperativen akuten Nierenversagens [ANV] kommt bei kardiochirurgischen Patienten eine wichtige Bedeutung zu, da hierdurch eine effektive Fokussierung prophylaktischer und therapeutischer Maßnahmen auf Patienten mit erhöhtem ANV-Risiko erfolgen kann. Thakar et al. publizierten 2005 einen Score zur präoperativen Abschätzung des ANV-Risikos, mit dem an einem großen monozentrischen Validierungs-Kollektiv die Inzidenz eines postoperativen dialysepflichtigen ANV mit hoher Präzision vorausgesagt werden konnte. Um die Übertragbarkeit dieses Scores auf andere Patientenkollektive zu prüfen, wurde der Score retrospektiv bei 3508 kardiochirurgischen Patienten der Universitätsklinik Göttingen angewandt. Es zeigte sich zwar ein qualitativ gleicher Zusammenhang zwischen Score-Wert und ANV-Risiko, die prognostische Aussagekraft war jedoch, gemessen an der Fläche unter der ROC-Kurve, deutlich reduziert. Mögliche Ursachen hierfür können zum einen die zum Teil unscharfe Definition einzelner präoperativer Risikofaktoren [z.B. Herzinsuffizienz] sein. Darüber hinaus können zum anderen auch unterschiedlich ausgeprägte intra- und postoperative Einflussfaktoren für abweichende prognostische Aussagekraft des Scores verantwortlich sein. Auch war die ANV-Inzidenz bei Patienten des Göttinger Kollektivs erheblich höher, als bei Patienten mit gleichem Score-Wert aus dem Validierungs-Kollektiv von Thakar. Als Kriterium für ein akutes Nierenversagen wurde von Thakar der Einsatz eines Nierenersatzverfahrens festgelegt. Da die Voraussetzungen für den Beginn einer Nierenersatztherapie, abgesehen von wenigen zwingenden Indikationen, in Abhängigkeit von lokalen Standards in weiten Bereichen variieren können, limitiert diese Definition des Endpunktes ebenfalls die Überprüfbarkeit der Daten an anderen Patientenkollektiven. Diese Ergebnisse legen den Schluss nahe, dass die Übertragbarkeit der Score-Ergebnisse durch objektivere Kriterien des ANV, wie z.B. nach AKIN-Klassifikation, erheblich verbessert werden könnte. 


\section{Abbildungsverzeichnis}

Abb. 1 : Niere

Abb. 2 : GISI-Maske mit obligaten Daten

Abb. 3 : GISI-Maske mit fakultativen Daten: objektiv [links], subjektiv [rechts]

Abb. 4 : GISI-Maske mit objektiv-obligaten Daten am Beispiel: Art des kardiochirurgischen

Eingriffs 22

Abb. 5 : GISI-Maske für das Merkmal ANV / kein ANV .... 22

Abb. 6 : GISI-Maske mit objektiv-obligaten Daten am Beispiel: Art des kardiochirurgischen Eingriffs in Form eines Freitextfeldes. .23

Abb. 7 : Beispiel ROC-Kurve 25

Abb. 8 : Verteilung der einzelnen Score-Werte 32

Abb. 9 : Häufigkeit der Risiko-Gruppen 32

Abb.10 : Inzidenz des ANV in den einzelnen Score-Werten 35

Abb.11 : Inzidenz des ANV in den Risiko-Gruppen 35

Abb.12 : Gegenüberstellung ROC-Kurve angewandt am Göttinger Kollektiv [links] mit der ROC-Kurve des Original-Thakar-Scores [rechts]. 36

Abb.13 : ROC-Kurve des Original-Scores angewandt am Göttinger Kollektiv [links] und ROC-Kurve des modifizierten Scores [rechts]. 41 


\section{Tabellenverzeichnis}

Tab. 1 : Risikofaktoren mit zugehörigen Scorepunkten...................................................... 10

Tab. 2 : Prärenale Ursachen für akute Niereninsuffizienz ................................................... 13

Tab. 3 : Intrarenale Ursachen für akute Niereninsuffizienz .................................................. 15

Tab. 4 : Postrenale Ursachen für akute Niereninsuffizienz................................................. 15

Tab. 5 : Einteilung der erforderlichen Daten................................................................... 20

Tab. 6 : Beobachtete Häufigkeiten in einer Kreuztabelle ................................................... 26



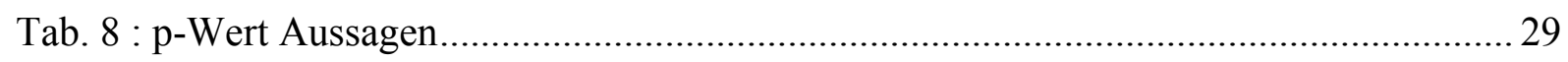

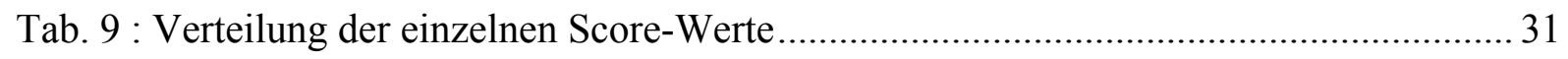

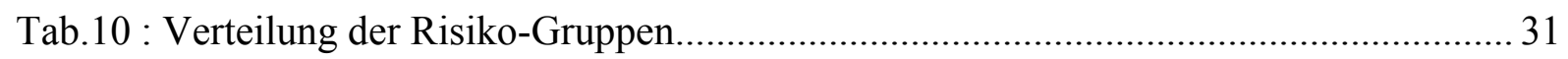

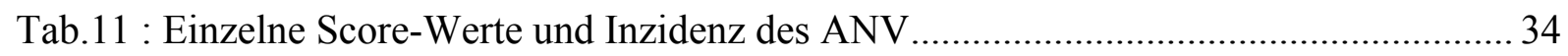

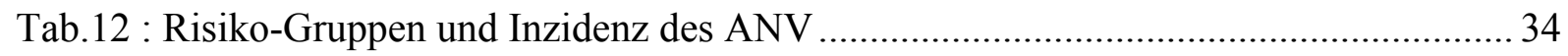

Tab.13 : Vergleich monovariate Analyse der kategorischen Risikofaktoren für das ANV ... 38

Tab.14 : Vergleich univariate Analyse der kontinuierlichen Risikofaktoren für das ANV ..... 39

Tab.15 : Vergleich multivariate Analyse der Thakar-definierten ANV Risikofaktoren.......... 40 


\section{Literaturverzeichnis}

Abel RM, Buckley MJ, Austen WG, Barnett GO, Beck CH, Fischer JE (1976): "Acute postoperative renal failure in cardiac surgical patients." J Surg Res 20(4): 341-8.

Bagshaw SM, George C, Bellomo R (2008): "A comparison of the RIFLE and AKIN criteria for acute kidney injury in critically ill patients." Nephrol Dial Transplant 23(5): 1569-74.

Barr LF, Kolodner K (2008): "N-acetylcysteine and fenoldopam protect the renal function of patients with chronic renal insufficiency undergoing cardiac surgery." Crit Care Med 36(5): 1427-35.

Basnakian AG, Kaushal GP, Shah SV (2002): "Apoptotic pathways of oxidative damage to renal tubular epithelial cells." Antioxid Redox Signal 4(6): 915-24.

Bellomo R, Bonventre J, Macias W, Pinsky M (2005): "Management of early acute renal failure: focus on post-injury prevention." Curr Opin Crit Care 11(6): 542-7.

Bellomo R, Kellum JA, Ronco C (2007): "Defining and classifying acute renal failure: from advocacy to consensus and validation of the RIFLE criteria." Intensive Care Med 33(3): 40913.

Bent P, Tan HK, Bellomo R, Buckmaster J, Doolan L, Hart G, Silvester W, Gutteridge G, Matalanis G, Raman J, Rosalion A, Buxton BF (2001): "Early and intensive continuous hemofiltration for severe renal failure after cardiac surgery." Ann Thorac Surg 71(3): 832-7.

Bergman AS, Odar-Cederlof I, Westman L, Bjellerup P, Hoglund P, Ohqvist G (2002): "Diltiazem infusion for renal protection in cardiac surgical patients with preexisting renal dysfunction." J Cardiothorac Vasc Anesth 16(3): 294-9.

Bonventre JV, Weinberg JM (2003): "Recent advances in the pathophysiology of ischemic acute renal failure." J Am Soc Nephrol 14(8): 2199-210.

Bourgeois E, Bataille A, Jacob L (2009): "[Perioperative modifications in kidney function]." Presse Med 38(11): 1621-9.

Bove T, Calabro MG, Landoni G, Aletti G, Marino G, Crescenzi G, Rosica C, Zangrillo A (2004): "The incidence and risk of acute renal failure after cardiac surgery." J Cardiothorac Vasc Anesth 18(4): 442-5.

Candela-Toha A, Elias-Martin E, Abraira V, Tenorio MT, Parise D, de Pablo A, Centella T, Liano F (2008): "Predicting acute renal failure after cardiac surgery: external validation of two new clinical scores." Clin J Am Soc Nephrol 3(5): 1260-5. 
Chertow GM, Lazarus JM, Christiansen CL, Cook EF, Hammermeister KE, Grover F, Daley J (1997): "Preoperative renal risk stratification." Circulation 95(4): 878-84.

Chiou WL, Hsu FH (1975): "Pharmacokinetics of creatinine in man and its implications in the monitoring of renal function and in dosage regimen modifications in patients with renal insufficiency." J Clin Pharmacol 15(5-6): 427-34.

Cockcroft DW, Gault MH (1976): "Prediction of creatinine clearance from serum creatinine." Nephron 16(1): 31-41.

Conlon PJ, Stafford-Smith M, White WD, Newman MF, King S, Winn MP, Landolfo K (1999): "Acute renal failure following cardiac surgery." Nephrol Dial Transplant 14(5): 115862.

Costantini TW, Fraga G, Fortlage D, Wynn S, Fraga A, Lee J, Doucet J, Bansal V, Coimbra R (2009): "Redefining renal dysfunction in trauma: implementation of the Acute Kidney Injury Network staging system." J Trauma 67(2): 283-7; discussion 287-8.

de Moraes Lobo EM, Burdmann EA, Abdulkader RC (2000): "Renal function changes after elective cardiac surgery with cardiopulmonary bypass." Ren Fail 22(4): 487-97.

Demirkilic U, Kuralay E, Yenicesu M, Caglar K, Oz BS, Cingoz F, Gunay C, Yildirim V, Ceylan S, Arslan M, Vural A, Tatar H (2004): "Timing of replacement therapy for acute renal failure after cardiac surgery." J Card Surg 19(1): 17-20.

Di Bella I, Da Col U, Ciampichini R, Affronti A, Santucci A, Fabbri M, Sapia F, Ragni T (2007): "[Validation of a new scoring system to predict the risk of postoperative acute renal failure in cardiac surgery]." G Ital Cardiol (Rome) 8(5): 306-10.

Doddakula K, Al-Sarraf N, Gately K, Hughes A, Tolan M, Young V, McGovern E (2007): "Predictors of acute renal failure requiring renal replacement therapy post cardiac surgery in patients with preoperatively normal renal function." Interact Cardiovasc Thorac Surg 6(3): 314-8.

Durmaz I, Buket S, Atay Y, Yagdi T, Ozbaran M, Boga M, Alat I, Guzelant A, Basarir S (1999): "Cardiac surgery with cardiopulmonary bypass in patients with chronic renal failure." J Thorac Cardiovasc Surg 118(2): 306-15.

Elahi MM, Lim MY, Joseph RN, Dhannapuneni RR, Spyt TJ (2004): "Early hemofiltration improves survival in post-cardiotomy patients with acute renal failure." Eur J Cardiothorac Surg 26(5): 1027-31.

Evenepoel P (2004): "Acute toxic renal failure." Best Pract Res Clin Anaesthesiol 18(1): 37 52. 
Frost L, Pedersen RS, Lund O, Hansen OK, Hansen HE (1991): "Prognosis and risk factors in acute, dialysis-requiring renal failure after open-heart surgery." $\underline{\text { Scand J Thorac Cardiovasc }}$ Surg 25(3): 161-6.

Gibney N, Hoste E, Burdmann EA, Bunchman T, Kher V, Viswanathan R, Mehta RL, Ronco C (2008): "Timing of initiation and discontinuation of renal replacement therapy in AKI: unanswered key questions." Clin J Am Soc Nephrol 3(3): 876-80.

Gross ML, Adamczak M, Ritz E (2005): "Renal failure and ACE inhibition: how much is too much?" Z Kardiol 94(2): 81-6.

Gummert JF, Funkat A, Beckmann A, Schiller W, Hekmat K, Ernst M, Haverich A (2009): "Cardiac surgery in Germany during 2008. A report on behalf of the German Society for Thoracic and Cardiovascular Surgery." Thorac Cardiovasc Surg 57(6): 315-23.

Heise D, Rentsch K, Braeuer A, Friedrich M, Quintel M (2010): "Comparison of urinary neutrophil glucosaminidase-associated lipocalin, cystatin $\mathrm{C}$, and alpha(1)-microglobulin for early detection of acute renal injury after cardiac surgery." Eur J Cardiothorac Surg.

Herold G: Kap.: Akutes Nierenversagen, Innere Medizin, Eigenverlag, Köln 2010: 605-609.

Heyman SN, Rosen S, Darmon D, Goldfarb M, Bitz H, Shina A, Brezis M (2000):

"Endotoxin-induced renal failure. II. A role for tubular hypoxic damage." Exp Nephrol 8(4-5): 275-82.

Joannes-Boyau O, Honore PM, Boer W, Rose T (2010): "Septic acute kidney injury and tubular apoptosis: never a Lone Ranger." Intensive Care Med 36(3): 385-8.

Jones DR, Lee HT (2007): "Protecting the kidney during critical illness." Curr Opin Anaesthesiol 20(2): 106-12.

Karkouti K, Beattie WS, Wijeysundera DN, Rao V, Chan C, Dattilo KM, Djaiani G, Ivanov J, Karski J, David TE (2005): "Hemodilution during cardiopulmonary bypass is an independent risk factor for acute renal failure in adult cardiac surgery." J Thorac Cardiovasc Surg 129(2): 391-400.

Kellum JA, Leblanc M, Gibney RT, Tumlin J, Lieberthal W, Ronco C (2005): "Primary prevention of acute renal failure in the critically ill." Curr Opin Crit Care 11(6): 537-41.

Köhler H: Kap.: Akute Niereninsuffizienz, in:TIM's Thieme Innere, Thieme Verlag, Stuttgart 1999: 1389 - 1396.

Lassnigg A, Schmidlin D, Mouhieddine M, Bachmann LM, Druml W, Bauer P, Hiesmayr M (2004): "Minimal changes of serum creatinine predict prognosis in patients after cardiothoracic surgery: a prospective cohort study." J Am Soc Nephrol 15(6): 1597-605. 
Lassnigg A, Schmid ER, Hiesmayr M, Falk C, Druml W, Bauer P, Schmidlin D (2008): "Impact of minimal increases in serum creatinine on outcome in patients after cardiothoracic surgery: do we have to revise current definitions of acute renal failure?" Crit Care Med 36(4): 1129-37.

Leacche M, Winkelmayer WC, Paul S, Lin J, Unic D, Rawn JD, Cohn LH, Byrne JG (2006): "Predicting survival in patients requiring renal replacement therapy after cardiac surgery." Ann Thorac Surg 81(4): 1385-92.

Mangano CM, Diamondstone LS, Ramsay JG, Aggarwal A, Herskowitz A, Mangano DT (1998): "Renal dysfunction after myocardial revascularization: risk factors, adverse outcomes, and hospital resource utilization. The Multicenter Study of Perioperative Ischemia Research Group." Ann Intern Med 128(3): 194-203.

Martinelli SM, Patel UD, Phillips-Bute BG, Milano CA, Archer LE, Stafford-Smith M, Shaw AD, Swaminathan M (2009): "Trends in cardiac surgery-associated acute renal failure in the United States: a disproportionate increase after heart transplantation." Ren Fail 31(8): 633-40.

MaWhinney S, Brown ER, Malcolm J, VillaNueva C, Groves BM, Quaife RA, Lindenfeld J, Warner BA, Hammermeister KE, Grover FL, Shroyer AL (2000): "Identification of risk factors for increased cost, charges, and length of stay for cardiac patients." Ann Thorac Surg 70(3): 702-10.

McCullough PA (2008): "Radiocontrast-induced acute kidney injury." Nephron Physiol 109(4): p61-72.

Mehta RH, Grab JD, O'Brien SM, Bridges CR, Gammie JS, Haan CK, Ferguson TB, Peterson ED (2006): "Bedside tool for predicting the risk of postoperative dialysis in patients undergoing cardiac surgery." Circulation 114(21): 2208-16; quiz 2208.

Mehta RL, Kellum JA, Shah SV, Molitoris BA, Ronco C, Warnock DG, Levin A (2007): "Acute Kidney Injury Network: report of an initiative to improve outcomes in acute kidney injury." Crit Care 11(2): R31.

Mitter N, Shah A, Yuh D, Dodd OJ, Thompson RE, Cameron D, Hogue CW (2010): "Renal injury is associated with operative mortality after cardiac surgery for women and men." $\underline{\mathrm{J}}$ Thorac Cardiovasc Surg: im Druck.

Morabito S, Guzzo I, Solazzo A, Muzi L, Pistolesi V, Pierucci A (2006): "[Acute renal failure following cardiac surgery.]." G Ital Nefrol 23 Suppl 36: S52-60.

Morricone L, Ranucci M, Denti S, Cazzaniga A, Isgro G, Enrini R, Caviezel F (1999):

"Diabetes and complications after cardiac surgery: comparison with a non-diabetic population." Acta Diabetol 36(1-2): 77-84. 
Oliveira TM, Oliveira GM, Klein CH, Souza ESNA, Godoy PH (2010): "[Mortality and complications of coronary artery bypass grafting in Rio de Janeiro, from 1999 to 2003.]." Arq Bras Cardiol.

Palomba H, de Castro I, Neto AL, Lage S, Yu L (2007): "Acute kidney injury prediction following elective cardiac surgery: AKICS Score." Kidney Int 72(5): 624-31.

Perry TE, Muehlschlegel JD, Liu KY, Fox AA, Collard CD, Shernan SK, Body SC (2010): "Plasma neutrophil gelatinase-associated lipocalin and acute postoperative kidney injury in adult cardiac surgical patients." Anesth Analg 110(6): 1541-7.

Praught ML, Shlipak MG (2005): "Are small changes in serum creatinine an important risk factor?" Curr Opin Nephrol Hypertens 14(3): 265-70.

Provenchere S, Plantefeve G, Hufnagel G, Vicaut E, De Vaumas C, Lecharny JB, Depoix JP, Vrtovsnik F, Desmonts JM, Philip I (2003): "Renal dysfunction after cardiac surgery with normothermic cardiopulmonary bypass: incidence, risk factors, and effect on clinical outcome." Anesth Analg 96(5): 1258-64, table of contents.

Ranucci M, Romitti F, Isgro G, Cotza M, Brozzi S, Boncilli A, Ditta A (2005): "Oxygen delivery during cardiopulmonary bypass and acute renal failure after coronary operations." Ann Thorac Surg 80(6): 2213-20.

Rodrigues AJ, Evora PR, Bassetto S, Alves Junior L, Scorzoni Filho A, Araujo WF, Vicente WV (2009): "[Risk factors for acute renal failure after heart surgery]." Rev Bras Cir Cardiovasc 24(4): 441-6.

Rosner MH, Okusa MD (2006): "Acute kidney injury associated with cardiac surgery." Clin J Am Soc Nephrol 1(1): 19-32.

Ryckwaert F, Boccara G, Frappier JM, Colson PH (2002): "Incidence, risk factors, and prognosis of a moderate increase in plasma creatinine early after cardiac surgery." Crit Care Med 30(7): 1495-8.

Sirvinskas E, Andrejaitiene J, Raliene L, Nasvytis L, Karbonskiene A, Pilvinis V, Sakalauskas J (2008): "Cardiopulmonary bypass management and acute renal failure: risk factors and prognosis." Perfusion 23(6): 323-7.

Sisillo E, Ceriani R, Bortone F, Juliano G, Salvi L, Veglia F, Fiorentini C, Marenzi G (2008): "N-acetylcysteine for prevention of acute renal failure in patients with chronic renal insufficiency undergoing cardiac surgery: a prospective, randomized, clinical trial." Crit Care Med 36(1): 81-6.

Stallwood MI, Grayson AD, Mills K, Scawn ND (2004): "Acute renal failure in coronary artery bypass surgery: independent effect of cardiopulmonary bypass." Ann Thorac Surg 77(3): 968-72. 
Star RA (1998): "Treatment of acute renal failure." Kidney Int 54(6): 1817-31.

Taniguchi FP, Souza AR, Martins AS (2007): "Cardiopulmonary bypass time as a risk factor for acute renal failure." Rev Bras Cir Cardiovasc 22(2): 201-5.

Thakar CV, Yared JP, Worley S, Cotman K, Paganini EP (2003 a): "Renal dysfunction and serious infections after open-heart surgery." Kidney Int 64(1): 239-46.

Thakar CV, Liangos O, Yared JP, Nelson DA, Hariachar S, Paganini EP (2003 b): "Predicting acute renal failure after cardiac surgery: validation and re-definition of a risk-stratification algorithm." Hemodial Int 7(2): 143-7.

Thakar CV, Liangos O, Yared JP, Nelson D, Piedmonte MR, Hariachar S, Paganini EP (2003 c): "ARF after open-heart surgery: Influence of gender and race." Am J Kidney Dis 41(4): $742-51$.

Thakar CV, Arrigain S, Worley S, Yared JP, Paganini EP (2005): "A clinical score to predict acute renal failure after cardiac surgery." J Am Soc Nephrol 16(1): 162-8.

Weiss C.: "Basiswissen medizinische Statistik; 5.überarbeitete Auflage." Springer Verlag, Heidelberg 2010: 334 .

Whelton A (2000): "Renal and related cardiovascular effects of conventional and COX-2specific NSAIDs and non-NSAID analgesics." Am J Ther 7(2): 63-74.

Wijeysundera DN, Karkouti K, Dupuis JY, Rao V, Chan CT, Granton JT, Beattie WS (2007): "Derivation and validation of a simplified predictive index for renal replacement therapy after cardiac surgery." JAMA 297(16): 1801-9.

Wort und Bild Verlag/ Ibelherr/Szczesny (2005). Nierenversagen. http://www.apothekenumschau.de/Nierenversagen.

Yallop KG, Smith DC (2004): "The incidence and pathogenesis of acute renal failure following cardiac surgery, and strategies for its prevention." Ann Card Anaesth 7(1): 17-31. 


\section{Danksagung}

Herrn PD Dr. Anselm Bräuer möchte ich für die Überlassung dieses Dissertationsthemas danken.

Mein besonderer Dank gilt Herrn Dr. Daniel Heise, der trotz seines hohen beruflichen Engagements ein hervorragender Betreuer war. Er war stets in allen Fragen zu jeder Zeit ansprechbar und motivierend. Von seinen Ideen und kritischen Korrekturen konnte ich stark profitieren.

Danken möchte ich auch Elke Meyerhof, die aufopferungsvoll Korrekturen las. Herrn Michael Schäfer gilt der Dank für die Hilfe bei den vielen Formatierungen und für seine endlose Geduld. 


\section{Lebenslauf}

Am 16.04.1981 wurde ich in Herford als Tochter von Jörg-Michael Mann, kaufmännischer Angestellter, und Andrea Sundermann, Krankenschwester, geboren.

Ich besuchte von 1987 bis 1991 die Grundschule Diebrocker Straße in Herford und anschließend von 1991 bis 2000 das Königin-Mathilde-Gymnasium in Herford.

Während dieser Zeit absolvierte ich ein Schulhalbjahr am Lycée Hédouart-Hériot in Voiron, Frankreich. Meine Abiturprüfung legte ich im Juni $2000 \mathrm{ab}$.

Nach meiner Schulzeit begann ich im Oktober 2000 eine Ausbildung zur Krankenschwester im Herz- und Diabeteszentrum NRW, Bad Oeynhausen, die ich im September 2003 mit dem Staatsexamen abschloss.

Ich erhielt für Oktober 2003 die Zulassung für das Studium der Humanmedizin an der GeorgAugust-Universität Göttingen. In den Semesterferien arbeitete ich als Krankenschwester zunächst auf einer kardiochirurgischen Normalstation, später auf einer chirurgischinternistischen 22-Betten- Intensivstation.

Am 6. März 2006 legte ich den I. Abschnitt der Ärztlichen Prüfung ab. Während meines klinischen Studienabschnitts famulierte ich in den Fächern Anästhesiologie, Innere Medizin, Allgemeinmedizin und Kinderchirurgie.

Mein erstes Tertial im Praktischen Jahr absolvierte ich in der Chirurgie im Centre Hospitalier Territorial in Nouméa, Neukaledonien. Der Schwerpunkt lag in der Unfallchirurgie und Orthopädie. Im Anschluss durchlief ich mein zweites Tertial im Fach Innere Medizin im Klinikum Herzberg (Harz). Hier wählte ich den Schwerpunkt in den Bereichen Kardiologie und Gastroenterologie. Im letzten Tertial meines Praktischen Jahres war ich in meinem Wahlfach Anästhesiologie im Kantonsspital Liestal in der Schweiz tätig.

Den II. Abschnitt der Ärztlichen Prüfung bestand ich am 19. Mai 2010. 